\title{
Temporary Neurotrophin Treatment Prevents Deafness- Induced Auditory Nerve Degeneration and Preserves Function
}

\author{
Dyan Ramekers, ${ }^{1,2}$ Huib Versnel, ${ }^{1,2}$ @Stefan B. Strahl, ${ }^{3}$ Sjaak F.L. Klis, ${ }^{1,2}$ and Wilko Grolman ${ }^{1,2}$ \\ ${ }^{1}$ Department of Otorhinolaryngology and Head \& Neck Surgery and ${ }^{2}$ Brain Center Rudolf Magnus, University Medical Center Utrecht, 3508 GA, Utrecht, \\ The Netherlands, and ${ }^{3}$ Research and Development, MED-EL Medical Electronics, 6020 Innsbruck, Austria
}

After substantial loss of cochlear hair cells, exogenous neurotrophins prevent degeneration of the auditory nerve. Because cochlear implantation, the current therapy for profound sensorineural hearing loss, depends on a functional nerve, application of neurotrophins is being investigated. We addressed two questions important for fundamental insight into the effects of exogenous neurotrophins on a degenerating neural system, and for translation to the clinic. First, does temporary treatment with brain-derived neurotrophic factor (BDNF) prevent nerve degeneration on the long term? Second, how does a BDNF-treated nerve respond to electrical stimulation? Deafened guinea pigs received a cochlear implant, and their cochleas were infused with BDNF for 4 weeks. Up to 8 weeks after treatment, their cochleas were analyzed histologically. Electrically evoked compound action potentials (eCAPs) were recorded using stimulation paradigms that are informative of neural survival. Spiral ganglion cell (SGC) degeneration was prevented during BDNF treatment, resulting in 1.9 times more SGCs than in deafened untreated cochleas. Importantly, SGC survival was almost complete 8 weeks after treatment cessation, when 2.6 times more SGCs were observed. In four eCAP characteristics (three involving alteration of the interphase gap of the biphasic current pulse and one involving pulse trains), we found large and statistically significant differences between normal-hearing and deaf controls. Importantly, for BDNF-treated animals, these eCAP characteristics were near normal, suggesting healthy responsiveness of BDNF-treated SGCs. In conclusion, clinically practicable short-term neurotrophin treatment is sufficient for long-term survival of SGCs, and it can restore or preserve SGC function well beyond the treatment period.

Key words: BDNF; cochlear implant; eCAP; guinea pig; hearing loss; spiral ganglion cell

Significance Statement

Successful restoration of hearing in deaf subjects by means of a cochlear implant requires a healthy spiral ganglion cell population. Deafness-induced degeneration of these cells can be averted with neurotrophic factors. In the present study in deafened guinea pigs, we investigated the long-term effects of temporary (i.e., clinically practicable) treatment with brain-derived neurotrophic factor (BDNF). We show that, after treatment cessation, the neuroprotective effect remains for at least 8 weeks. Moreover, for the first time, it is shown that the electrical responsiveness of BDNF-treated spiral ganglion cells is preserved during this period as well. These findings demonstrate that treatment of the auditory nerve with neurotrophic factors may be relevant for cochlear implant users.

\section{Introduction}

Profound hearing loss is often caused by cochlear hair cell loss. Cochlear implants (CIs) essentially replace hair cells by encoding

\footnotetext{
Received Jan. 9, 2015; revised June 25, 2015; accepted July 3, 2015.

Author contributions:D.R., H.V., S.B.S.,S.F.L.K., and W.G. designed research;D.R. performed research;S.B.S. contributed unpublished reagents/analytic tools; D.R. and H.V. analyzed data; D.R., H.V., and S.F.L.K. wrote the paper.

This work was supported by MED-EL GmbH, Innsbruck, Austria. We thank Ferry Hendriksen for histological processing, Koen van Riessen for histological analysis, René van de Vosse for technical support, and Roland Hessler at MED-EL, Innsbruck, for the electrode arrays.

W.G. received an unrestrictive research grant from MED-EL GmbH for this study and unrestrictive research grants from Cochlear and Advanced Bionics. The remaining authors declare no competing financial interests.
}

sound and conveying the signal by means of pulsatile electrical stimulation to the spiral ganglion cells (SGCs), which form the auditory nerve (Géléoc and Holt, 2014). SGCs progressively degenerate in response to hair cell loss (Ylikoski et al., 1974; Spoendlin, 1975; Versnel et al., 2007), which in human CI users has been shown to be negatively correlated to speech perception

Correspondence should be addressed to Dr. Huib Versnel, Department of Otorhinolaryngology and Head \& Neck Surgery, Brain Center Rudolf Magnus, University Medical Center Utrecht, F.02.504, P.0. Box 85500, 3508 GA, Utrecht, The Netherlands. E-mail: h.versnel@umcutrecht.nl.

DOI:10.1523/JNEUROSCI.0096-15.2015

Copyright $\odot 2015$ the authors $\quad 0270-6474 / 15 / 3512331-15 \$ 15.00 / 0$ 
(Seyyedi et al., 2014). Treatment with exogenous neurotrophic factors, such as brain-derived neurotrophic factor (BDNF) or neurotrophin-3 (NT-3), prevents SGC degeneration (for review, see Ramekers et al., 2012).

For treatment with neurotrophic factors to become suitable for clinical application, long-term effectiveness is crucial, with respect to both SGC survival and responsiveness to electrical stimulation (Staecker and Garnham, 2010). If continuous support is necessary for SGC survival (Pettingill et al., 2011), cell-based or viral-based delivery of neurotrophic factors may be appropriate (e.g., Wise et al., 2011; Atkinson et al., 2014). However, these methods face practical and ethical objections. Increased levels of neurotrophic factors may have unpredictable effects (e.g., neoplasia) on the long-term, and it may be difficult to stop the treatment if necessary. From an ethical perspective, using genetically modified cells or viruses for human applications might be considered undesirable. For single temporary delivery (e.g., through simple and clinically feasible administration onto the round window membrane) (Havenith et al., 2011, 2015), a sustained protective effect is required. Such a prolonged effect has been demonstrated for periods of 2-4 weeks (Maruyama et al., 2008; Agterberg et al., 2009; Fransson et al., 2010). However, these periods are relatively short, leaving the question of whether degeneration has only been postponed. Therefore, the first objective of the present study is to assess SGC survival after a more extended period ( 8 weeks) following cessation of BDNF treatment, sufficiently long to observe effects of withdrawal. If temporary treatment only postpones the degeneration, a loss of $>50 \%$ would be expected (van Loon et al., 2013), whereas SGC loss would be negligible if temporary treatment triggers a self-supporting mechanism in SGCs (Ramekers et al., 2012).

The second objective is to examine the effect of neurotrophin treatment on the nerve's responsiveness by means of electrically evoked compound action potential (eCAP) recordings. eCAPs provide a more direct measure of functional effects of neurotrophin treatment than the commonly used electrically evoked auditory brainstem responses (eABRs) (Shinohara et al., 2002; Endo et al., 2005; Shepherd et al., 2005; Chikar et al., 2008; Maruyama et al., 2008; Agterberg et al., 2009; Havenith et al., 2011, 2015; Leake et al., 2011). We applied various stimulation paradigms, which may discriminate between healthy and degenerated nerves. Specifically, we examined the effect of an interphase gap (IPG) in the biphasic current pulse, the magnitude of which has been shown to correlate with SGC survival (PradoGuitierrez et al., 2006; Ramekers et al., 2014). Furthermore, temporal response properties, including neural recovery characteristics, were assessed with multiple-pulse stimulation paradigms (Ramekers et al., 2015). The main question is whether the BDNF-treated nerve's response resembles that of a healthy nerve or of an untreated degenerated nerve.

This study examines whether brief neurotrophin treatment has long-term protective effects on the auditory nerve, including responsiveness to electrical stimulation. In general terms, this study contributes to our knowledge of the role of neurotrophins in neurodegenerative disorders.

\section{Materials and Methods}

Animals and experimental design. Forty female albino guinea pigs (Dunkin Hartley; 250-350 g) were obtained from Harlan Laboratories and kept under standard laboratory conditions (food and water ad libitum; lights on between 7:00 A.M. and 7:00 P.M.; temperature $21^{\circ} \mathrm{C}$; humidity 60\%). All animals had bilateral normal hearing before any experimental treatment, as assessed with click-evoked ABRs.

Animals were divided into five experimental groups as depicted in Figure 1. One group served as normal-hearing controls $(\mathrm{NH}, \mathrm{N}=6)$. The remaining groups ( 14 weeks deaf, $14 W D, N=6$; BDNF-treated, $B D N F 0$, $N=9$; BDNF-treated with an additional 4 week period after cessation of the treatment, $B D N F 4, N=10$; and BDNF-treated with an additional 8 week period after cessation of the treatment, BDNF8, $N=9$ ) were exposed to ototoxic treatment 2 weeks before implantation. In all animals, the right ears were implanted with an intracochlear electrode array combined with a cannula, which was connected to a subcutaneously placed osmotic pump. The pump reservoir was filled with PBS either with or without BDNF. Four weeks after implantation, the osmotic pumps were surgically removed to end the treatment. Depending on the treatment schedule, animals were killed 4, 8, or 12 weeks after implantation (Fig. 1). Electrophysiological measurements were performed immediately after each surgical procedure and immediately before termination and histological processing of the cochleas. eCAP recordings after implantation and after pump removal were performed in a brief session of $2-3 \mathrm{~min}$, so as not to allow possible neurotrophic effects of electrical stimulation to occur, even though such effects were assumed to be negligible (Agterberg et al., 2010). All surgical and experimental procedures were approved by the Animal Care and Use Committee of Utrecht University (DEC 2010.I.08.103)

Cochlear implantation of normal-hearing animals involves stimulation of the functional organ of Corti as well as stimulation of SGCs, but the stable condition of the healthy cochlea was necessary to cancel out any confounding effects of chronic implantation. Although electrically evoked activity of hair cells (also known as electrophonics) is to be expected in normal-hearing animals, electrophonics do not influence the eCAP because the latency of electrophonic spikes is $1-2$ ms longer than that of spikes directly evoked at the SGC soma or peripheral process 
A

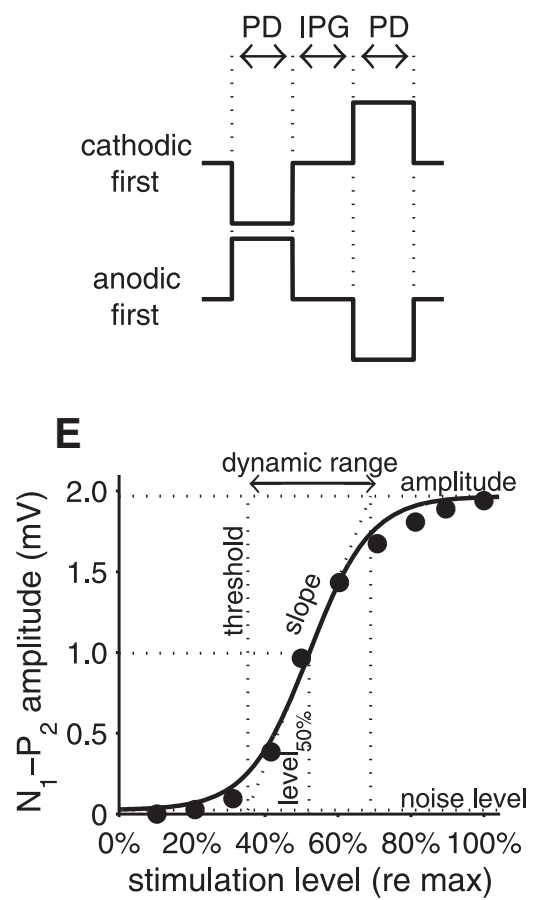

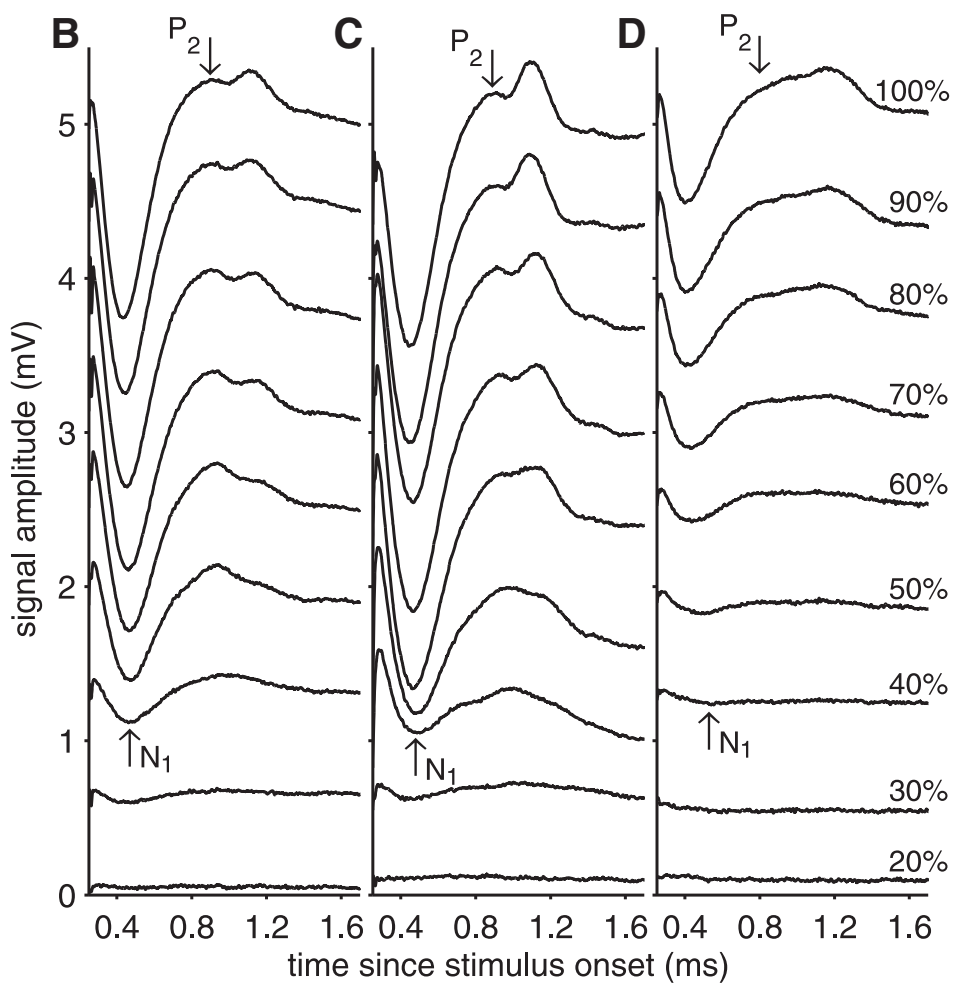

Figure 2. A, Schematic representation of the pulses used for eCAP recordings. In single-pulse paradigms, PD was $50 \mu$ s and IPG varied between 2.1 and $30 \mu s$; in multiple-pulse paradigms, both $P D$ and IPG were $30 \mu$ s. Pulse polarity was alternated to reduce the stimulus artifact in the recording. $\boldsymbol{B}-\boldsymbol{D}$, eCAP examples for different current levels (percentage of maximum current level) for an NH animal ( $\boldsymbol{B}$ ), a BDNFO animal ( $\boldsymbol{C}$, and a 14 WD animal (D). , Example of an input- output function derived from the eCAP $\mathrm{N}_{1}-\mathrm{P}_{2}$ amplitude (filled circles). Solid line indicates the fitted Boltzmann curve (see Eq. 1). Dashed lines indicate the eCAP characteristics that were derived from the Boltzmann equation.

(Javel and Shepherd, 2000; Stronks et al., 2010). We have specifically chosen normal-hearing animals as positive controls, rather than acutely deafened animals, for the following reasons. First, after acute deafening, the cochlear condition is not stable, which may result in varying eCAP outcomes during the recording session. Second, the isolated effects of implantation over time (separate from deafness-induced degeneration) can be investigated only in nondeafened chronically implanted animals. Third, we compare the present data with data from our previous studies (Ramekers et al., 2014, 2015), in which we had two groups of deafened animals ( 2 weeks deaf with mild loss of SGCs, and 6 weeks deaf with substantial loss of SGCs).

Deafening procedure. Animals were anesthetized by intramuscular injection of dexmedetomidine (Dexdomitor; $0.25 \mathrm{mg} / \mathrm{kg}$ ) and ketamine (Narketan; $40 \mathrm{mg} / \mathrm{kg}$ ), and click-evoked ABRs were recorded to confirm normal hearing (for details, see Ramekers et al., 2014). Thresholds $<40$ $\mathrm{dB}$ peak equivalent SPL (peSPL) were considered to indicate normal hearing. Deafening was done by subcutaneous injection of kanamycin (Sigma-Aldrich; $400 \mathrm{mg} / \mathrm{kg}$ ) and subsequent infusion of furosemide (Centrafarm; $100 \mathrm{mg} / \mathrm{kg}$ ) into the external jugular vein, which has been shown to eliminate the majority of both inner and outer hair cells (West et al., 1973; Versnel et al., 2007).

Osmotic pump preparation and cochlear implantation. We followed procedures for BDNF delivery that were comparable with those performed previously in our laboratory (Agterberg et al., 2008, 2009). Approximately $40 \mathrm{~h}$ before cochlear implant surgery, the Alzet osmotic pumps (model 2004; reservoir volume: $200 \mu \mathrm{l}$; flow rate $0.25 \mu \mathrm{l} / \mathrm{h}$; Durect) were filled with PBS containing $1 \%$ guinea pig serum (SigmaAldrich) for $\mathrm{NH}$ and $14 \mathrm{WD}$ groups. For the BDNF-treated groups, 100 $\mu \mathrm{g} / \mathrm{ml}$ BDNF (PeproTech) was added. Pumps were then incubated in sterile $\mathrm{PBS}$ at $37^{\circ} \mathrm{C}$ until implantation. With a flow rate of $0.25 \mu \mathrm{l} / \mathrm{h}$, the total quantity of BDNF infused into the cochlea after $28 \mathrm{~d}$ was $\sim 17 \mu \mathrm{g}$.

Anesthesia was induced as described for deafening above; in addition, $0.05 \mathrm{mg} / \mathrm{kg}$ atropine was given by intramuscular injection to reduce bronchial secretion. Click-evoked ABRs were recorded to confirm a suc- cessful deafening procedure (i.e., threshold shift $>50 \mathrm{~dB}$ ) before initiation of the implantation procedure.

The skull was exposed, and five transcranial screws ( $1.2 \mathrm{~mm}$ diameter) were placed for eCAP stimulation and for eCAP and ABR recording purposes. These screws were placed $2 \mathrm{~cm}$ anterior to bregma (ABR reference electrode); $1 \mathrm{~cm}$ posterior to bregma ( $A B R$ active electrode); $1 \mathrm{~cm}$ to the left of bregma (eCAP recording reference electrode); and two screws $1 \mathrm{~cm}$ to the right of bregma (ABR ground electrode and eCAP stimulation reference electrode). An additional screw was positioned just anterior to bregma for anchoring of the electrode array connector onto the skull. Via a retro-auricular approach, the right bulla was opened to gain access to the basal turn of the cochlea. Within $1 \mathrm{~mm}$ from the round window, a $0.4 \mathrm{~mm}$ cochleostomy was drilled. The array/cannula was inserted through the cochleostomy into the scala tympani $\sim 4 \mathrm{~mm}$. The array had a diameter of $0.3 \mathrm{~mm}$ at the tip and slightly tapered so that it sealed off the cochleostomy; it consisted of two electrodes, located $\sim 0.5$ and $2.1 \mathrm{~mm}$ from the tip, and a $75 \mu \mathrm{m}$ diameter fluid outlet located in between. To ensure proper functioning of the electrodes and correct insertion of the array, electrode impedances were measured and eCAP recordings were tested.

The opening in the bulla was closed with glass ionomer cement (GC Fuji PLUS; GC), and the connector of the electrode array was fixed onto the skull with polymer dental cement (ProBase Cold; Ivoclar Vivadent $A G)$. The eCAP reference electrodes were soldered to the designated transcranial screws, which were then covered with dental cement. The cannula, which passed through the connector, was filled with sterile PBS (either with or without BDNF) before insertion into the cochlea; the flow moderator of the osmotic pump was attached, and the pump was subsequently placed subcutaneously anterior to the left shoulder.

Removal of the osmotic pump. To ensure treatment cessation, the osmotic pumps were surgically removed 4 weeks after implantation (Agterberg et al., 2009). Anesthesia was induced as described for deafening above. After carefully removing the encapsulating tissue, the osmotic pump was examined for signs of treatment failure (e.g., detachment of 
the cannula; opaque content of the cannula), and subsequently removed. The open cannula was tied off using nonabsorbable nylon sutures (Ethilon; Ethicon) and fixed to the subcutis. The remainder of the cannula had an estimated volume of $\sim 4 \mu \mathrm{l}$, which means that, after cessation of BDNF treatment, $0.4 \mu \mathrm{g}$ BDNF remained in the tied-off cannula. Following Fick's first law of diffusion, and given the diffusion constant of BDNF $\left(4.57 \times 10^{-7} \mathrm{~cm}^{2}\right.$ $\mathrm{s}^{-1}$ ) (Stroh et al., 2004), the amount of BDNF that would diffuse through a $75-\mu \mathrm{m}$-diameter cannula over $\sim 10 \mathrm{~cm}$ in 8 weeks' time is in the order of only $1 \mathrm{ng}$.

Surgical procedure for eCAP experiment. At the end of the treatment period (Fig. 1), extensive eCAP recordings were done. Preparations for these recording sessions were done as has been described previously (Ramekers et al., 2014). In brief, anesthesia was initiated with Hypnorm (Vetapharma; $0.5 \mathrm{ml} / \mathrm{kg}$ i.m.), followed by a gas mixture of $2 \%$ isoflurane evaporated in $\mathrm{O}_{2}$ and $\mathrm{N}_{2} \mathrm{O}(1: 2)$. Atropine $(0.05$ $\mathrm{mg} / \mathrm{kg}$ ) was given to reduce bronchial secretion. The animals were then tracheostomized and were artificially ventilated throughout the recording session.

CAPs. For a detailed description of eCAP recording settings and stimulation paradigms, we refer to Ramekers et al. (2014) for single-pulse and to Ramekers et al. (2015) for multiple-pulse stimulation.

A shielded cable was used to connect the electrode array and reference electrodes to a MED-EL PULSARCI ${ }^{100}$ cochlear implant (MED-EL). The implant was controlled by a PC via a Research Interface Box 2 (Department of Ion Physics and Applied Physics, University of Innsbruck, Innsbruck, Austria) and a National Instruments data acquisition card (PCI-6533, National Instruments). Stimulation and recording paradigms, as well as data analysis scripts, were created in MATLAB (version 7.11.0; The MathWorks).

Both stimulation and recording of eCAPs were done with monopolar configuration; the most apical of the two intracochlear electrodes was used for stimulation, and the most basal one for recording. Biphasic current pulses were presented with alternating polarity to reduce stimulation artifact, whereas recordings to a subthreshold stimulus were subtracted to eliminate measurement onset artifacts.

Single-pulse paradigm. The phase duration (PD) of the current pulses was $50 \mu$ s; the IPG was varied from 2.1 to $30 \mu$ s (Fig. 2A). Maximum current levels were determined for each animal and each recording session individually, based on saturation of the input-output curves, or in some cases based on the maximum output level of the implant $(6.1 \mathrm{~V}$ in our setup), which could be the limiting factor in case of high impedances. The maximum charge per phase was $23 \mathrm{nC}$ on average (range among animals: $14-30 \mathrm{nC}$; mean range among groups: $21-24$ $\mathrm{nC}$ ). Ten current levels were applied in $10 \%$ steps of the thus determined maximum current level. The amplitude of the negative peak, $\mathrm{N}_{1}$, was defined as the difference in voltage between the $\mathrm{N}_{1}$ and the $\mathrm{P}_{2}$ peak (first positive peak following $\mathrm{N}_{1}$; see Fig. $2 B-D$ ). Input-output functions were fitted with a Boltzmann sigmoid, following Ramekers et al. (2014):

$$
V_{e C A P}=A+\frac{B}{1+e^{-\frac{I-C}{D}}},
$$

where $V$ is amplitude in $\mu \mathrm{V}, I$ is stimulus current in $\mu \mathrm{A}$, and $A-D$ are fitting parameters. $R^{2}$ was between 0.91 and 1 (0.99 on average). From these parameters, several variables were derived (Fig. $2 E$ ): the maximum
$\mathrm{N}_{1}$ amplitude (defined by $B$ ); the current level required to attain $50 \%$ of the maximum $\mathrm{N}_{1}$ amplitude (defined by $C$ ); the slope at $C$ (defined by $B / 4 D$ ); the threshold (defined by $C-2 D$, the current level at which the tangent to the curve at $C$ crosses $A$ ); and the dynamic range (defined by $4 D$ ). The $\mathrm{N}_{1}$ peak latency, averaged over the three highest current levels, was analyzed in addition to these input-output characteristics.

Multiple-pulse paradigms. Current levels for masker-probe and pulse train stimulation were $10 \%$ (for artifact reduction) and $100 \%$ of the previously defined maximum current level. Biphasic current pulses (30 $\mu$ sD and $30 \mu$ s IPG) were presented either in pulse pairs (masker-probe stimulation) with variable masker-probe interval (MPI; $0.4-16 \mathrm{~ms}$ in 18 steps) or in $100 \mathrm{~ms}$ pulse trains with variable interpulse interval (IPI; $0.4-16 \mathrm{~ms}$ in 10 steps).

The responses to the last 10 pulses of the pulse train were recorded individually; first the response after $N$ pulses in a $100 \mathrm{~ms}$ pulse train was recorded, then the responses after $N-1$ through $N-9$ pulses were separately recorded. In Figure 3, examples of eCAP recordings from a masker-probe paradigm (Fig. $3 A$ ) and from a pulse train paradigm (Fig. $3 B$ ) are shown for all used pulse intervals.

Thus obtained $\mathrm{N}_{1}$ amplitudes were normalized to the amplitude obtained with a single pulse at maximum current level, for each animal and each recording session separately. Figure 4 shows examples of normalized amplitudes for the last 10 pulses of the pulse train. Fourier analysis of these 10 amplitudes yielded the average eCAP amplitude (DC component; used for recovery function fitting) and the amplitude of the oscillation around this average (AC component, i.e., amplitude of the most dominant frequency; used for eCAP amplitude modulation analysis).

To assess the recovery function of the pulse train data, the amplitudes versus pulse interval were fitted with a commonly used exponential function (e.g., Morsnowski et al., 2006; Botros and Psarros, 2010; Ramekers et al., 2015) as follows: 

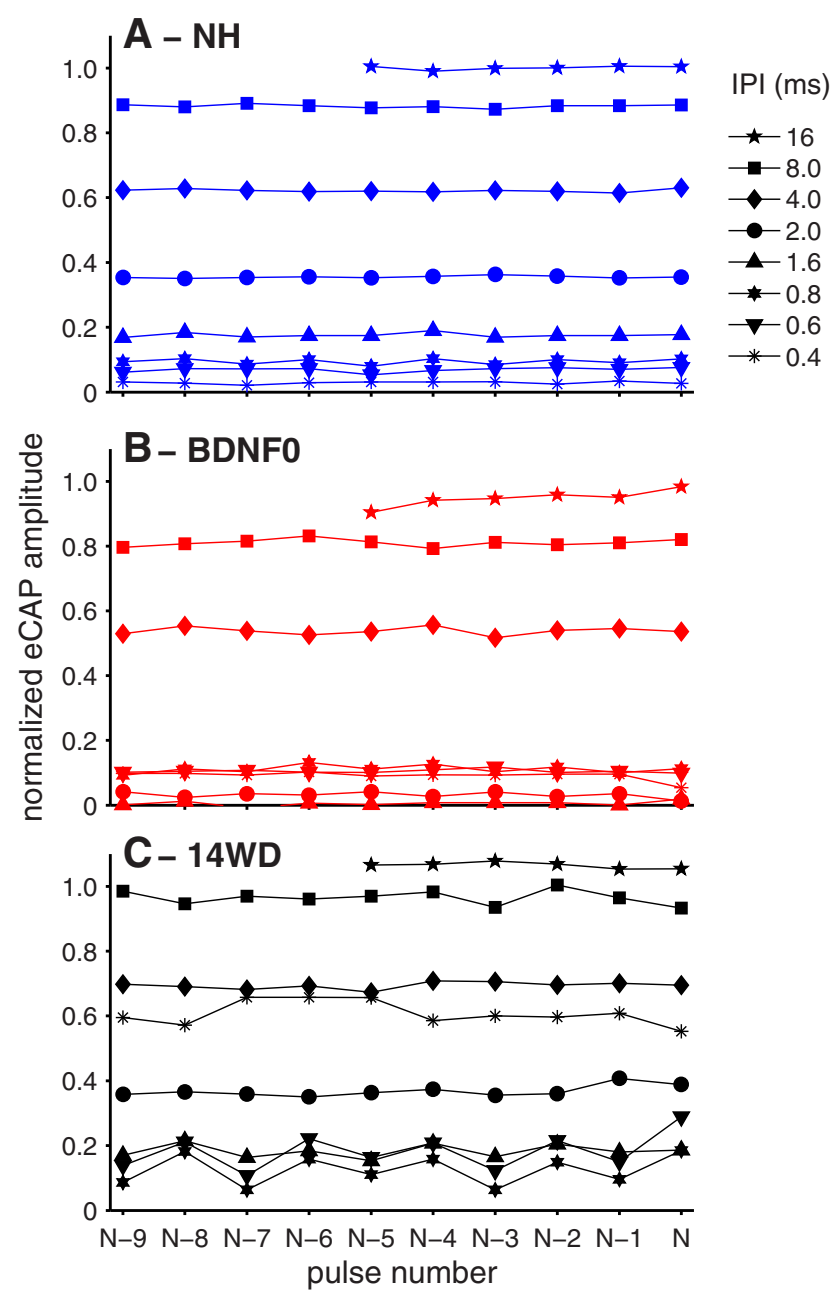

Figure 4. eCAP amplitudes plotted for the last 10 pulses of pulse trains with different IPIs at maximum current level for the following: $\boldsymbol{A}$, an NH animal; $\boldsymbol{B}$, a BDNFO animal; and $\boldsymbol{C}$, a $14 W D$ animal.

$$
e C A P=A \cdot\left(1-e^{-\frac{I P I-t_{0}}{\tau}}\right),
$$

where $e C A P$ is the normalized eCAP amplitude for a given interpulse interval IPI, $A$ is the maximum eCAP amplitude evoked by a probe pulse after a sufficiently long IPI (comparable to a single-pulse-evoked eCAP), $\tau$ is the recovery time constant, and $t_{0}$ is the absolute refractory period.

In accordance with previous findings (Ramekers et al., 2015), maskerprobe recovery functions deviated from this conventional recovery function as they displayed a nonmonotonic or shoulder-shaped course (Fig. $5 A$ ). We therefore used a two-component exponential function to describe masker-probe recovery as follows:

$$
e C A P=A \cdot\left(1+c \cdot e^{-\frac{M P I-t_{0}}{\tau_{A}}}\right) \cdot\left(1-e^{-\frac{M P I-t_{0}}{\tau_{B}}}\right),
$$

where $e C A P$ is the normalized eCAP amplitude evoked by the probe for a given masker-probe interval MPI, $A$ is the maximum eCAP amplitude evoked by a probe pulse after a sufficiently long MPI, $c$ is a dimensionless constant defining the ratio between the two exponential components, $\tau_{A}$ is the recovery time constant of the first exponential, $\tau_{B}$ is the recovery time constant of the second exponential, and $t_{0}$ is the absolute refractory period.

Histology. After completion of the final eCAP recording session, all animals were killed, and both their right implanted and left nonimplanted cochleas were harvested. Processing and analysis were largely performed as previously described (van Loon et al., 2013). After intral- abyrinthine fixation and decalcification, three semithin $(1 \mu \mathrm{m})$ midmodiolar sections were cut from each cochlea at $60 \mu \mathrm{m}$ intervals and stained with $1 \%$ methylene blue, $1 \%$ azur B, and $1 \%$ borax in distilled water.

Using a Leica DC300F digital camera mounted on a Leica DMRA light microscope and a $40 \times$ oil-immersion objective (Leica Microsystems), micrographs of each transection of Rosenthal's canal ( 2 basal, 2 middle, and 3 apical transections), as well as the organ of Corti were obtained. Within each transection of Rosenthal's canal, the number of Type I and Type II SGCs was counted and packing density was averaged across all three sections. In two of the three sections, the average perikaryal area was determined for Type I SGCs with a visible nucleus using ImageJ (version 1.42q; National Institutes of Health). Subsequently, both packing density and perikaryal area were first averaged to obtain one value per cochlear location (base, middle, and apex); these were then averaged to obtain a single value per cochlea. Because the likelihood of detecting an individual SGC depends on its perikaryal size, the average packing density was corrected for perikaryal size as previously described (Coggeshall and Lekan, 1996; van Loon et al., 2013). Hair cell presence was sampled in midmodiolar sections (Versnel et al., 2007). Hair cell counts included hair cells with a nucleus, a cilia bundle, or a clear cochlear hair-cell-like outline.

Statistical analysis. Differences in ABR threshold shifts were evaluated with a one-way ANOVA (for differences among animal groups) or a paired-samples Student's $t$ test (within NH animals after implantation). Changes in SGC packing density and perikaryal area after implantation, ototoxic treatment, or BDNF treatment were assessed with one-way ANOVA or Student's $t$ test; the Bonferroni correction was applied in case of post hoc multiple comparison. The differences in SGC packing density in BDNF-treated animals for the three cochlear locations separately were assessed using linear mixed-model analysis with cochlear location as covariate and time after deafening as factor, under the assumption of compound symmetry. For this analysis, cochlear location was defined as the distance from the round window, relative to the length of the basilar membrane (e.g., first basal turn: 0.21; helicotrema: 1.0).

Differences in absolute values of single-pulse eCAP characteristics (input-output characteristics and latency) were assessed with repeatedmeasures ANOVA, using IPG as repeats, and for time points $t=6$ (end of BDNF treatment) and $t=14$ (endpoint for groups BDNF8, NH, and $14 W D$ ) separately. The differential effect of IPG increase on eCAP characteristics among groups was evaluated with one-way ANOVA for time points $t=6$ and $t=14$ separately. To assess the longitudinal effect of implantation on eCAP characteristics, a linear mixed model was used with IPG as covariate and time (immediately upon implantation and after osmotic pump removal) as factor; for this analysis, only the $\mathrm{NH}$ eCAPs were used, so that neither deafening nor BDNF treatment confounded the data.

Differences in multiple-pulse eCAP characteristics (recovery and eCAP amplitude modulation) among groups were assessed with one-way ANOVA and post hoc multiple comparison with Bonferroni correction.

Linear regression was used to evaluate the relation between eCAP measures and SGC packing density in $\mathrm{NH}$ and $14 \mathrm{WD}$ animals. Using this linear relation, we predicted the eCAP measures for the average packing densities found for each of the BDNF treatment groups. The deviation between measured and predicted values in the BDNF-treated animals was analyzed using Student's $t$ tests. The SD of the predicted values was estimated by the residuals of the regression analysis.

All statistical tests were performed with SPSS version 20.0 for Windows (IBM).

\section{Results}

\section{Effect of deafening}

A paired-samples Student's $t$ test showed that there were no differences in hair cell counts between BDNF-treated and contralateral untreated ears (inner hair cells: $t_{(23)}=1.0 ; p=0.33$; outer hair cells: $\left.t_{(23)}=0.28 ; p=0.78\right)$. Hair cell counts from both ears were therefore averaged. In the $\mathrm{NH}$ group, $100 \%$ inner hair cells and $98 \%$ outer hair cells were present on average. For the deafened animal groups, between $0 \%$ and $2.2 \%$ of inner hair cells and 
between $0 \%$ and $13 \%$ of outer hair cells had survived. Differences in outer hair cell presence among the deafened groups were statistically significant [one-way ANOVA; $F_{(3,26)}=6.3 ; p=0.002$; post hoc multiple comparison with Bonferroni correction showed that differences between $B D N F 0$ and BDNF8 $(p=0.002)$ and between $B D N F 0$ and $14 W D(p=0.023)$ were statistically significant]. Because there were no differences in outer hair cell presence between BDNF8 and 14WD, outer hair cell survival was most likely related to time after deafening, rather than to BDNF or control treatment.

Click-evoked ABR threshold shifts 2 weeks after the ototoxic treatment were 81 $\mathrm{dB}$ on average (range, 59-89 dB). In case the ABR threshold could not be reached with the maximum click level $(\sim 105 \mathrm{~dB}$ peSPL), the threshold shift was defined as the difference between the ABR threshold before deafening and the maximum click level. These threshold shifts did not significantly differ among the deafened groups (one-way ANOVA; $F_{(3,29)}=0.64, p=0.59$ ). Additional ABR recordings during the final eCAP recording session (6-14 weeks after deafening) did not show any further changes of the ABR threshold.

\section{Effect of implantation}

In all implanted ears (regardless of treatment), fibrosis or ossification was regularly observed in the scala tympani around the electrode array. A significant $10 \mathrm{~dB}$ ABR threshold shift (from 28 to $38 \mathrm{~dB}$ peSPL) was observed for the $\mathrm{NH}$ animals' right implanted ears (paired-samples Student's $t$ test; $t_{(5)}=2.8, p=0.02$ ), which was most likely caused by direct insertion-induced trauma to the organ of Corti or by the secondary fibrous tissue growth around the electrode array in the scala tympani.

\section{Assessment of successful BDNF treatment and eCAP recordings}

Four weeks after cochlear implantation and onset of the treatment (termination of the BDNFO group; pump removal for the other groups), the connection of the cannula to the osmotic pump was examined. In one BDNF8 animal, the cannula was disconnected from the pump at this time point, and failure of BDNF treatment was confirmed with histological analysis after termination 8 weeks later: the SGC packing density was similar to that of $14 W D$ animals. In a second BDNF8 animal, the cannula was partly ruptured at the flow moderator of the osmotic pump. As with the previous case, the SGC packing density of this animal was indistinguishable from that of $14 W D$ animals. SGC packing densities from both animals were identified as statistical outliers in the BDNF8 group by SPSS, and both animals were hence excluded from further analysis.

Of the 38 animals that received treatment as planned, useful eCAPs could be recorded in all except for one BDNFO animal because the eCAP threshold for this animal was unusually high (i.e., near the maximum output voltage of the stimulator). Singlepulse and masker-probe data presented here are obtained from the remaining 37 animals $(N H, N=6 ; 14 W D, N=6 ; B D N F 0$, $N=8 ; B D N F 4, N=10 ; B D N F 8, N=7)$. Finally, reliable eCAPs in response to pulse trains could not be obtained in two $B D N F O$ animals and one BDNF4 animal because in these animals pulse train stimulation gave exceptionally large stimulation artifacts, which obscured the $\mathrm{N}_{1}$ peak. Pulse train data are therefore presented for 34 animals.

\section{Light micrographs of Rosenthal's canal}

In Figure 6, representative examples of transections of Rosenthal's canal in the upper basal turn are shown. SGCs in an $\mathrm{NH}$ cochlea are typically densely packed (Fig. 6A); 6 weeks after deafening, substantial SGC loss was observed and the remaining cells appear smaller, as exemplified by the left untreated ear of a BDNF0 animal (Fig. 6B). Four week treatment with BDNF of the right ear in the same $B D N F 0$ animal showed enhanced survival of SGCs and an increase in cell size (Fig. $6 C)$. Fourteen weeks after deafening, SGCs in an untreated cochlea (14WD) had degenerated further (Fig. 6D) relative to the $6 \mathrm{WD}$ condition (Fig. 6B). The effect of BDNF 8 weeks after cessation of the treatment is still evident (Fig. 6E), showing many more cells than in the untreated ear. Compared with the condition immediately after the end of the treatment period (Fig. 6C), the cell size was clearly reduced.

\section{SGC packing density}

In Figure 7, quantified SGC packing densities across all cochlear sections are shown in group averages as a function of time after deafening. In addition to the implanted/treated right and contralateral left ears from the present study, data of the right ears of three groups from a previous study (Ramekers et al., 2014) are shown in this figure. The guinea pigs in these groups were acutely implanted and did not receive any neurotrophic treatment. The first of these three groups consists of six normal-hearing animals represented by the blue circle at time point $t=0$. The second consists of five 2 weeks deaf (2WD) animals denoted by the black triangle at $t=2$, the time point at which the animals in the present study were implanted and the BDNF treatment started. The third group contains six 6 weeks deaf animals ( $6 W D)$ and is denoted by the black triangle at $t=6$. The remaining data points are the implanted right ears (solid lines; filled symbols) and untreated contralateral ears (dashed lines; open symbols) from the present study. 

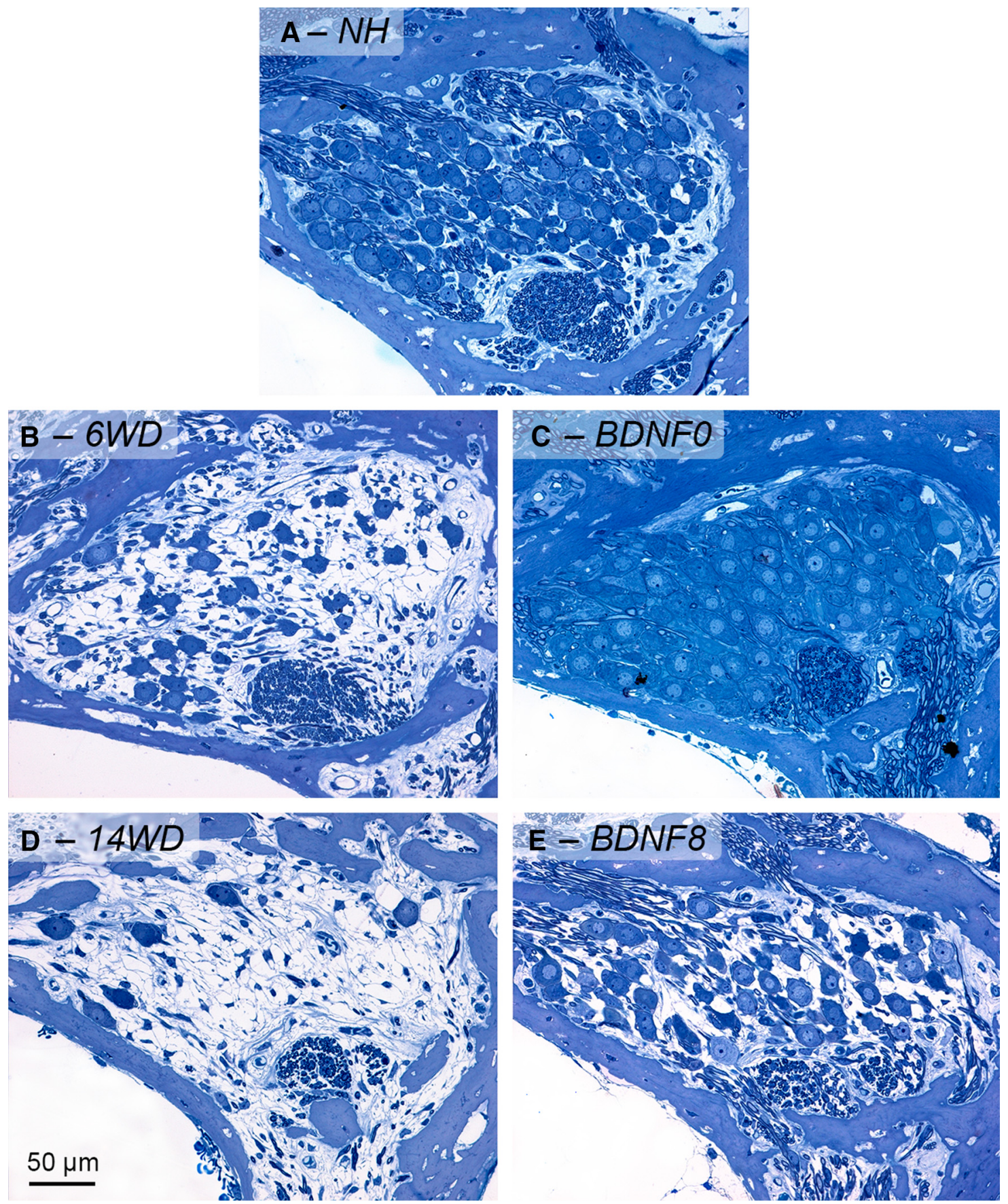

Figure 6. Examples of transections of Rosenthal's canal (upper basal turn) containing the SGCs in the following: $\boldsymbol{A}$, an NH animal (right implanted cochlea); $\boldsymbol{B}$, a BDNF0 animal (left untreated cochlea); $\boldsymbol{C}$, the same BDNFO animal (right implanted/BDNF-treated cochlea); $\boldsymbol{D}$, a 14WD animal (right implanted cochlea); and $\boldsymbol{E}$, a BDNF8 animal (right implanted/BDNF-treated cochlea).

There were no statistically significant differences among the three groups of normal-hearing ears (one-way ANOVA; $F_{(2,15)}=$ $0.75 ; p=0.49)$, indicating that neither cochlear implantation nor infusion of PBS into the cochlea had any effect on the number of SGCs. SGC degeneration (black lines) was previously shown to be significant in the three acutely implanted groups (Ramekers et al., 2014); here, it persisted beyond these 6 weeks as demonstrated by the $14 W D$ group [Student's $t$ test: $6 W D-14 W D$ (right ears only); $\left.t_{(10)}=2.6 ; p=0.014\right]$. Progressive SGC degeneration was successfully abolished during the 4 week treatment with BDNF (SGC packing density in $B D N F O$ animals virtually identical to that in $2 \mathrm{WD}$ animals, and 1.9 times that in $6 \mathrm{WD}$ animals). Remarkably, SGC degeneration did not recommence 4 or 8 weeks after cessa- tion of the BDNF treatment (SGC packing density in BDNF8 animals on average 2.6 times that in $14 W D$ animals). For a more detailed examination, the SGC packing density for the BDNFtreated ears is shown for the three cochlear locations separately in Figure 7 (inset). There appeared to be location-dependent survival of SGCs after BDNF treatment: whereas the packing density in the basal region did not decrease after treatment cessation, it did slightly decrease from week 10 to 14 in the middle region, and apical SGCs appeared to be largely unaffected by the treatment even during the 4 week treatment period itself. Linear mixedmodel analysis using cochlear location as covariate and time after deafening as factor (groups $2 W D, B D N F 0, B D N F 4$, and BDNF8) showed that the course of SGC packing density over time (i.e., 
among groups) was indeed dependent on cochlear location (interaction effect time $\times$ location; $\left.F_{(3,54)}=6.9 ; p<0.001\right)$, whereas neither time after deafening nor location showed a clear significant main effect (location: $F_{(1,54)}=2.6 ; p=0.12$; time: $\left.F_{(3,37)}=2.8 ; p=0.052\right)$.

As expected, the SGC packing density of the unimplanted left ears of the deafened animals (BDNF0, BDNF4, BDNF8, $14 W D$; dashed lines) was similar to the implanted right ears of the deafened untreated animals (black solid lines). The somewhat larger difference between the left ears of the BDNF8 animals and both ears of the $14 W D$ animals at $t=14$ was not statistically significant (one-way ANOVA; $\left.F_{(2,16)}=2.7 ; p=0.09\right)$.

\section{SGC mean perikaryal area}

Group averages of mean SGC perikaryal area are shown as a function of time after deafening in Figure 8. PBS infusion and chronic cochlear implantation did not affect SGC size in the $N H$ animals (one-way ANOVA; $\left.F_{(2,15)}=0.75 ; p=0.49\right)$. As for SGC packing density in Figure 7, previously obtained data on the initial decrease in cell size 2 and 6 weeks after deafening (2WD and $6 W D)$ are shown in Figure 8. Compared with $6 W D$ animals and the untreated left ears of the BDNF8 animals, mean perikaryal area appeared to be larger for both ears of the 14WD animals; differences were, however, not statistically significant (one-way ANOVA with groups $6 W D, 14 W D$, and BDNF8 left ears; $\left.F_{(2,21)}=2.8 ; p=0.083\right)$.

BDNF treatment and subsequent treatment cessation did influence mean perikaryal area: immediately after treatment, cells were much larger (by $\sim 18 \%$ relative to the start of treatment), and 4 and 8 weeks later, the cells again had a size similar to that seen at the start of treatment. These effects were significant (oneway ANOVA with groups $2 W D, B D N F 0, B D N F 4$, and BDNF8; $F_{(3,26)}=5.3 ; p=0.005$; post hoc multiple comparison with Bonferroni correction yielded significant differences between $B D N F 0$ and BDNF4 $(p=0.018)$ and between BDNF0 and BDNF8 $(p=$ $0.009)$ ). No significant differences among treated and untreated ears were found after treatment cessation (one-way ANOVA; $\left.F_{(3,31)}=1.4 ; p=0.27\right)$.

\section{Distributions of SGC perikaryal area}

To assess the effects of deafening, BDNF treatment, and subsequent treatment cessation on cell size in more detail, the perikaryal areas of individual SGCs are shown in histograms in Figure 9. The main observation is that the apparent normal distribution of cell sizes in $\mathrm{NH}$ animals persists after deafening and is shifted toward the left. This notion implies that after deafening all SGCs become smaller (probably as a result of loss of neurotrophic support), rather than that a divergence emerges between the $\sim 25 \%$ cells that survive 14 weeks after deafening and those that degenerate during this period. BDNF-treated cells were noticeably larger than untreated deaf or $\mathrm{NH}$ animals, but mainly in the basal part of the cochlea. Although the distribution was somewhat skewed, there was no sign of bimodality of the distribution.
Finally, after cessation of the BDNF treatment, the mean cell size gradually decreased, approximating that of $14 \mathrm{WD}$ animals, and a normal distribution was preserved in these animals as well.

\section{Single-pulse eCAP recordings}

Examples of eCAP recordings to various current levels are shown for an $N H$ animal, a BDNFO animal, and a $14 W D$ animal in Figure $2 B-D$. Resulting input-output functions were fitted with a Boltzmann sigmoidal curve (Eq. 1; Fig. 2E). Group averages of the input-output characteristics thus obtained are shown in Figure 10. Because single-pulse eCAPs were recorded at three time points during the experimental period (after implantation, after pump removal, and, depending on the treatment schedule, 4 or 8 weeks later), the data shown in Figure 10 are partly pooled across groups. First, eCAP recordings from all deafened animals are grouped together for the recording session immediately following implantation; second, eCAPs from all BDNF-treated animals at the end of the treatment period (final recording session for $B D N F 0$; pump removal for BDNF4 and BDNF8 animals) are pooled. In addition, for various reasons, eCAP recordings immediately postoperatively were not possible in some animals, so that the number of animals per group for these sessions deviates from those in the final recording session (see figure legend).

Early effects of chronic implantation were assessed for $\mathrm{NH}$ animals by comparing eCAPs recorded immediately after implantation with those obtained after removal of the osmotic pump 4 weeks later. Linear mixed-model analysis, treating time as factor and IPG as covariate, showed statistically significant decreases in threshold (Figure $10 G, H ; F_{(6.8,1)}=9.8 ; p=0.017$ ), level $_{50 \%}$ (Figure $10 M, N ; F_{(8.1,1)}=11 ; p=0.010$ ), and latency 


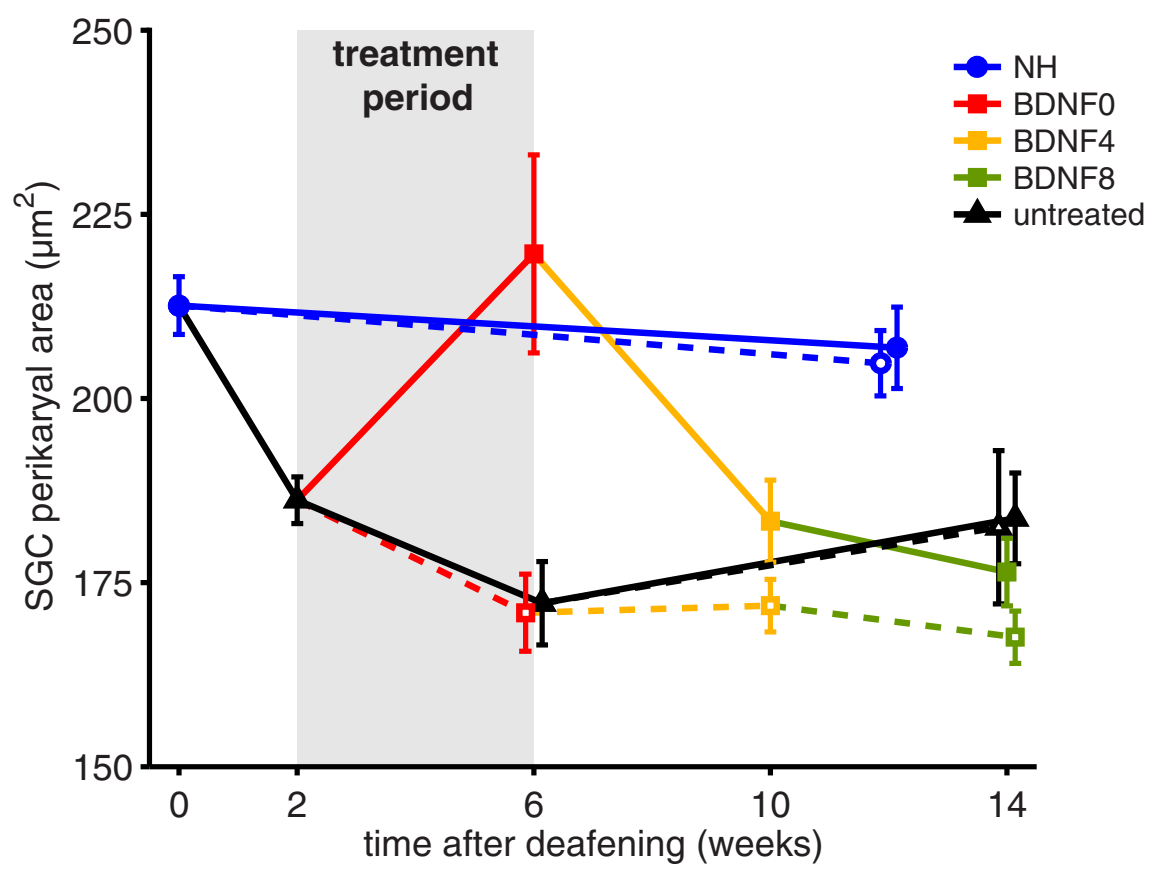

Figure 8. Group averages of $\mathrm{SGC}$ numerical mean perikaryal area as a function of time after deafening, analogous to Figure 7 . Filled symbols connected with solid lines represent implanted right ears. Open symbols connected with dashed lines represent unimplanted left ears. Blue symbols represent normal-hearing animals: at time point $t=0 \mathrm{NH}$ animals $(\mathrm{N}=6)$ from a previous study (Ramekers et al., 2014); and at $t=12$ the NH animals from the present study. Black triangles represent changes in mean SGC perikaryal area after deafening: the animal groups at time points $t=2$ and $t=6$ are from the aforementioned previous study $(N=5$ and $N=6$, respectively); the $14 W D$ animals are shown at $t=14$. BDNF treatment resulted in an increase in cell size; upon cessation of the treatment, mean perikaryal area became indistinguishable from that of untreated cells. (Connecting lines are shown purely for visualization purposes; connected data points indicate separate groups of animals.) Error bars indicate SEM.

change after cessation of the BDNF treatment for any of the eCAP characteristics (one-way ANOVA with groups BDNFO, BDNF4, and BDNF8; $p>0.12$ ).

\section{Masker-probe recovery functions}

eCAP waveforms in response to a probe stimulus in a masker-probe paradigm are exemplified for an $\mathrm{NH}$ animal in Figure $3 \mathrm{~A}$ (presented previously in Materials and Methods). The eCAP amplitude gradually decreased with decreasing MPI, until it disappeared altogether for the shortest MPI used $(0.3 \mathrm{~ms})$. Recovery functions were constructed from these eCAP amplitudes.

For three individual animals, maskerprobe recovery functions are shown in Figure $5 A$. For the $N H$ and $B D N F 0$ animals, a peak is present for MPIs $\sim 1 \mathrm{~ms}$, giving the recovery function a nonmonotonic appearance, and the curve of the 14WD animal shows a shoulder $\sim 1 \mathrm{~ms}$. Fitting of these data was therefore done with a twocomponent exponential function (Eq. 3), of which the first exponential described the peak $\sim 1 \mathrm{~ms}$ MPI, and the second described the (slower) recovery, reaching saturation for an MPI of $\sim 8 \mathrm{~ms}$. Corresponding fits are plotted as solid lines in the figure.

The average $R^{2}$ for masker-probe recovery function fitting was 0.96 . Group averages of the four parameters derived

(Figure $\left.10 P, Q ; F_{(7.3,1)}=45 ; p<0.001\right)$; amplitude, slope, and dynamic range did not change significantly (for all three: $p>$ $0.5)$.

Differences in absolute eCAP characteristics among groups were evaluated for time points $t=6$ and $t=14$ separately, treating IPG as repeats in repeated-measures ANOVA (Table 1). Significant differences among groups were found for all characteristics except for threshold. In general, the differences were largest between $\mathrm{NH}$ and untreated deafened animals (Fig. 10). Amplitude and slope were larger for $\mathrm{NH}$ animals than for the deafened animals, dynamic range and level ${ }_{50 \%}$ were larger for deafened than for $\mathrm{NH}$ animals, and latencies were longer for $\mathrm{NH}$ than for deafened animals. For time point $t=14$, the differences were often more pronounced than for $t=6$ (Table 1 ). A highly significant main effect of IPG was found for all eCAP characteristics for both time points: increasing the IPG resulted in an increase in amplitude, slope, dynamic range, and latency, and a decrease in threshold and level ${ }_{50 \%}$.

For all six eCAP characteristics, the change as a result of IPG increase from 2.1 to $30 \mu$ s is shown in Figure 10 (right-hand column). Differences in the magnitude of this change among groups (similar to the interaction effect IPG $\times$ group in the aforementioned repeated-measures ANOVA) were assessed with one-way ANOVA, the results of which are shown in Table 2. Subtle but consistent differences among groups were found for amplitude (Fig. 10C) and latency (Fig. 10R) at $t=14$, and for level ${ }_{50 \%}$ (Fig. 10O) for both time points. Importantly, examining these four particular differences, one observes that there were no differences in the IPG effect between $\mathrm{NH}$ and BDNF-treated animals, whereas these two groups significantly deviated from untreated deaf animals ( post hoc multiple comparison with Bonferroni correction; Table 2). The IPG effect did not from the fitted exponential function are depicted in Figure 11. The absolute refractory period $t_{0}$ was $\sim 0.5 \mathrm{~ms}$ for $\mathrm{NH}$ animals, which was significantly shorter than that for the $14 W D$ and BDNF4 animals $(\sim 0.6 \mathrm{~ms})$ (one-way ANOVA; $F_{(4,31)}=3.4 ; p=$ 0.022; post hoc multiple comparison with Bonferroni correction: $N H$-14WD, $p=0.048 ; N H$-BDNF4, $p=0.036$ ). Recovery time constant $\tau_{\mathrm{B}}$ was $\sim 0.5 \mathrm{~ms}$ faster for BDNF0 animals than for $\mathrm{NH}$ or $14 W D$ animals, and faster for BDNF4 animals than for $\mathrm{NH}$ animals (one-way ANOVA; $F_{(4,31)}=6.1 ; p<0.001$; post hoc multiple comparison with Bonferroni correction: $N H-B D N F 0$, $p=0.003 ; N H$-BDNF4, $p=0.014 ; 14 W D$-BDNF0, $p=0.024)$. Adding $t_{0}$ and $\tau_{\mathrm{B}}$ yields a single measure for recovery. This measure still varied significantly among groups, but effects of $t_{0}$ and $\tau_{\mathrm{B}}$ were partly cancelled (one-way ANOVA; $F_{(4,31)}=3.9 ; p=$ 0.011; post hoc multiple comparison with Bonferroni correction: 14WD-BDNF0: $p=0.019$ ).

The facilitation component of Equation 3, describing the peak $\sim 1$ ms MPI, was defined by facilitation constant $c$ (defining the amplitude) and time constant $\tau_{\mathrm{A}}$. There were no statistically significant differences in $c$ among groups (one-way ANOVA; $F_{(4,31)}=1.0$; $p=0.42)$. Time constant $\tau_{\mathrm{A}}$ was shorter for $14 W D, B D N F 0$, and BDNF4 animals than for $N H$ animals by $\sim 0.2 \mathrm{~ms}$ (one-way ANOVA; $F_{(4,31)}=5.0 ; p=0.003$; post hoc multiple comparison with Bonferroni correction: $N H-14 W D, p=0.007$; $N H-B D N F 0, p=$ 0.023; NH-BDNF4, $p=0.004)$.

\section{Pulse train responses}

Figure $3 B$ shows examples of eCAP recordings to the last $\left(N^{\text {th }}\right)$ pulse of $100 \mathrm{~ms}$ pulse trains with different IPIs (presented previously in Materials and Methods). As for the masker-probe example in Figure $3 A$, the eCAP amplitude decreased with shorter 


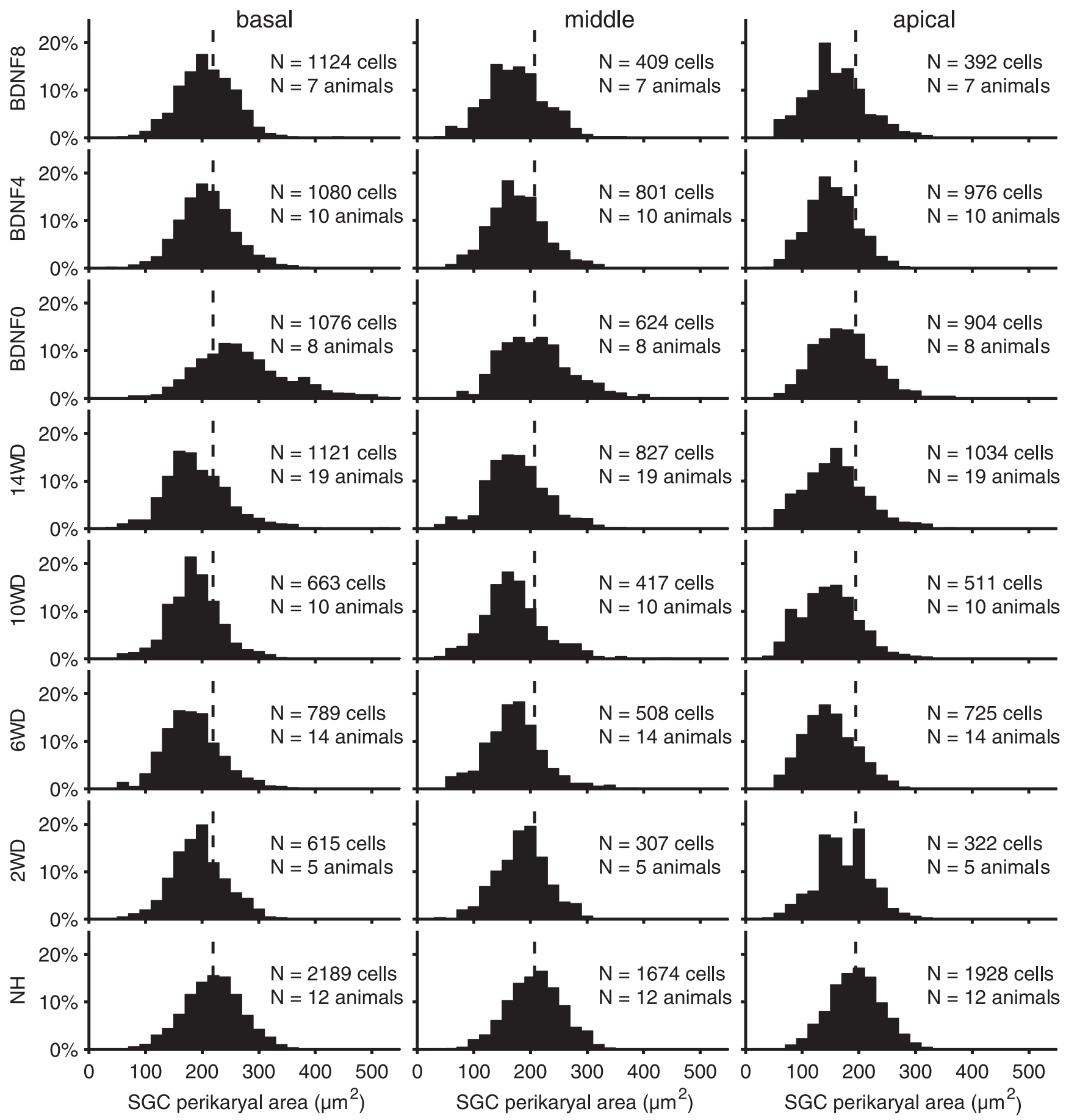

Figure 9. Distributions of $S G C s$ according to their perikaryal area in $20 \mu \mathrm{m}^{2}$ bins pooled across animals and plotted for three cochlear locations (columns) and for all animal groups (rows). Each histogram is plotted such that its total area represents $100 \%$ of all constituting cells. All cells that were included in the averages in Figure 8 are used in these histograms: $N H$ histograms contain cells from both ears from the $\mathrm{NH}$ group from the present study, and additionally from the right ears of $6 \mathrm{NH}$ animals from a previous study (Ramekers et al., 2014); the 6WD histograms contain cells from the left untreated ears from BDNF0 animals and from 66WD animals from the previous study; the 10WD data are formed by left untreated ears of BDNF4 animals; the $14 W D$ data represent a combined pool from both ears from $14 W D$ animals and the untreated left ears from BDNF8 animals. The number of cells and the number of animals from which these derived are shown in each respective plot. Dashed line indicates the mean SGC perikaryal area in NH cochleas, for each cochlear location separately.

pulse intervals, but this decrease was typically much faster for pulse trains than for masker-probe stimulation. The eCAP amplitudes for the last 10 pulses of pulse trains with different IPIs are plotted in Figure 4 for an $N H$, a $B D N F O$, and a $14 W D$ animal. Although the amplitude decreased with higher pulse rates, the amplitudes of the last 10 pulses were relatively stable over pulse number. For the $14 \mathrm{WD}$ animal, an oscillating pattern emerged at high pulse rates (Fig. 4C).
Pulse train recovery functions for three individual animals are shown in Figure 5B. The fitted exponential function (Eq. 2) is shown in solid lines. Compared with the masker-probe recovery functions in Figure $5 \mathrm{~A}$, these functions clearly show slower recovery. Furthermore, their course could be well described using the single exponential fit.

Pulse train recovery function fitting yielded recovery characteristics $t_{0}$ (absolute refractory period) and $\tau$ (recovery time con- 

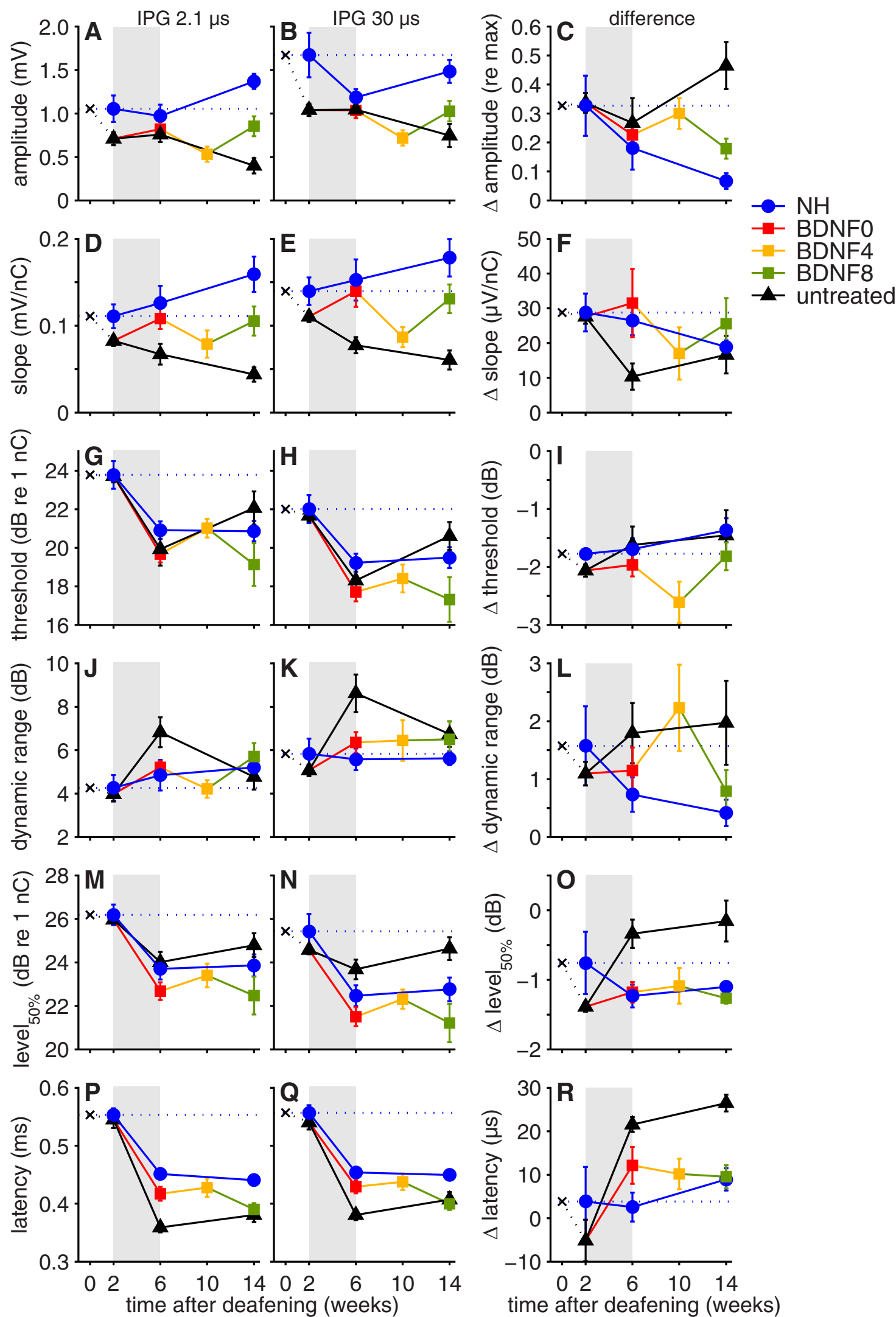

Figure 10. eCAP characteristics derived from fitting of the eCAP input-output functions with Boltzmann sigmoid curves plotted as a function of time after deafening. Phase duration was $50 \mu$ s for all pulses; IPG was $2.1 \mu$ s for the first column and $30 \mu$ s for the second column. In the third column, the difference between the first two columns (the IPG effect; IPG 30 - IPG $2.1 \mu$ s) is shown. eCAP characteristics are as follows: maximum amplitude $(\boldsymbol{A}-\boldsymbol{C})$, slope at inflection point $\mathbf{C}(\boldsymbol{D}-\boldsymbol{F})$, threshold $(\boldsymbol{G}-\boldsymbol{I})$, dynamic range $(\boldsymbol{J}-\boldsymbol{L})$, level ${ }_{50 \%}(\boldsymbol{M}-\mathbf{0})$, and latency $(\boldsymbol{P}-\boldsymbol{R})$. eCAPs were recorded directly after implantation $(t=2)$, after removal of the osmotic pump $(t=6)$, and at the end of the experimental procedure $(t=6$ for $B D N F 0 ; t=10$ for $B D N F 4 ; t=14$ for $N H, B D N F 8$, and $14 W D)$. For visualization purposes, the $\mathrm{NH}$ data at implantation are plotted at $t=0$ (black cross) as a theoretical starting point at time of deafening for the deafened groups, and in addition plotted as a blue dotted line for reference. At time point $t=2$, all deafened animals (all except NH) are grouped together (black triangle); these groups subsequently (Figure legend continues.) 
Table 1. Results from repeated-measures ANOVA, applied separately for each eCAP characteristic, and for time points $t=6$ and $t=14^{a}$

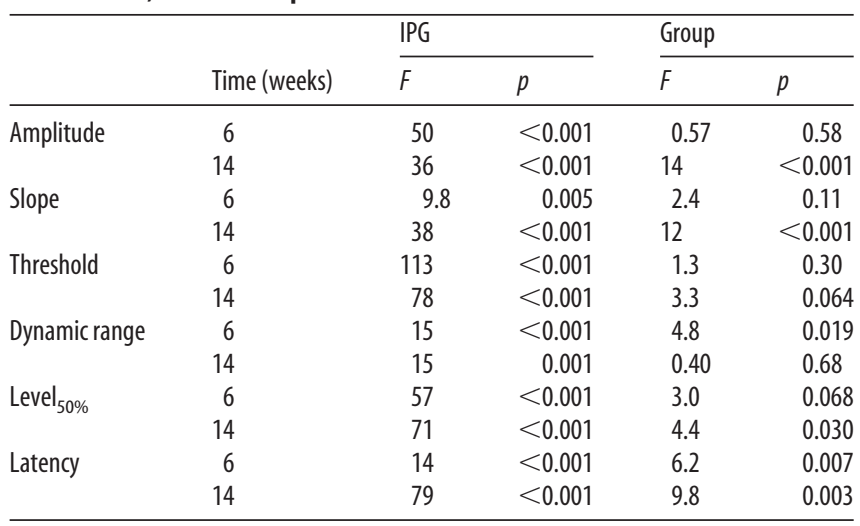

${ }^{a}$ Degrees of freedom for IPG (between): 1 ; for group (between): 2 ; degrees of freedom (within) at $t=6: 23$; at $t=$ $14 \cdot 16$

Table 2. Results from one-way ANOVA testing eCAP differences with IPG among groups, applied separately for each ECAP characteristic, and for time points $t=6$ and $t=14^{a}$

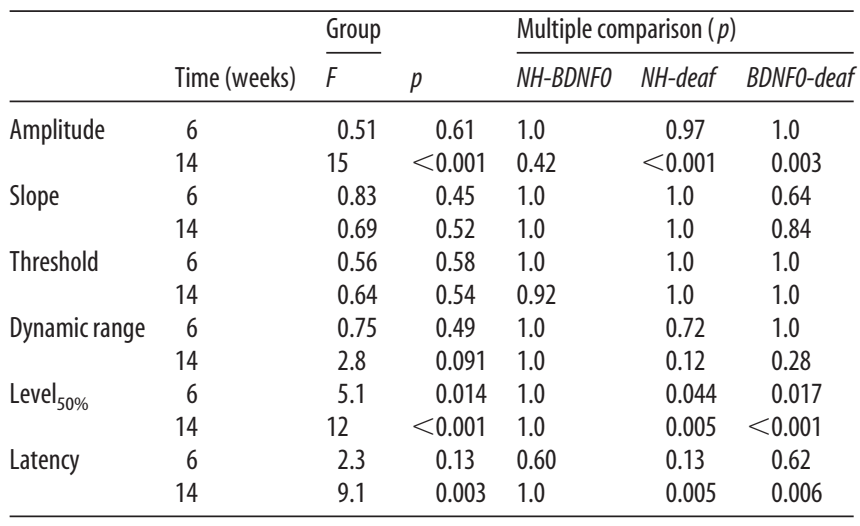

${ }^{a}$ Degrees of freedom for group (between): 2 ; degrees of freedom (within) at $t=6: 23$; at $t=14$ : 16 .

stant). Group averages of these characteristics are plotted in Figure 12, showing noticeably longer time constants compared with those obtained with the masker-probe paradigm $\left(t_{0}\right.$ and $\left.\tau_{\mathrm{B}}\right)$. The BDNF-treated animals had longer $t_{0}$ than the other groups by 0.5-0.8 ms, which was statistically significant for BDNFO and BDNF4 animals versus $14 \mathrm{WD}$ animals (one-way ANOVA; $F_{(4,29)}$ $=5.0 ; p=0.004$; post hoc multiple comparison with Bonferroni correction: $14 W D-B D N F 0, p=0.006 ; 14 W D-B D N F 4, p=$ 0.014 ). No significant differences were found for $\tau$ (one-way ANOVA; $\left.F_{(4,29)}=1.9 ; p=0.14\right)$. The combined measure $t_{0}+\tau$ varied significantly among groups, quite similarly to $t_{0}$ by itself (one-way ANOVA; $F_{(4,29)}=3.4 ; p=0.021$; post hoc multiple comparison with Bonferroni correction: 14WD-BDNF0: $p=$ $0.033)$.

\section{eCAP amplitude modulation}

For the $14 W D$ animal in Figure $4 C$, the amplitude displayed an alternating pattern for responses to high-rate pulse trains. In Fig-

$\leftarrow$

(Figure legend continued.) diverge into BDNF-treated (BDNF0, BDNF4, and BDNF8) and untreated animals (14WD) at $t=6$. Data points at time points after $t=6$ represent data from separate (unmixed) groups. Summaries of the statistical analysis of these data are shown in Tables 1 and 2. Gray bars represent the BDNF or control treatment period. Error bars indicate SEM.NH: $N=5$ at $t=2$ and $t=6, N=6$ at $t=14$; untreated: $N=19$ at $t=2, N=5$ at $t=$ $6, N=6$ at $t=14 ;$ BDNF-treated: $N=16$ at $t=6, N=10$ at $t=10, N=7$ at $t=14$.
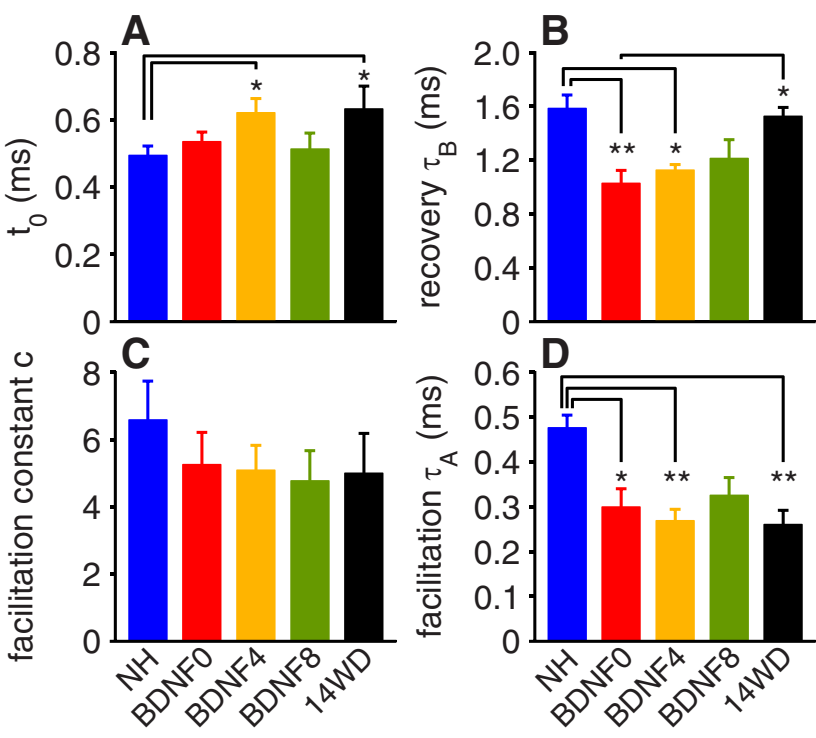

Figure 11. Group averages of masker-probe recovery characteristics. $A$, Absolute refractory period $t_{0}$. $\boldsymbol{B}$, Recovery time constant $\tau_{\mathrm{B}}$. $\boldsymbol{C}$, Facilitation time constant $\boldsymbol{C}$. $\boldsymbol{D}$, Facilitation time constant $\tau_{\mathrm{A}} . N H, N=6 ; B D N F 0, N=8 ; B D N F 4, N=10 ; B D N F 8, N=7 ; 14 W D, N=6 .{ }^{*} p<$ $0.05 .{ }^{* *} p<0.01$. Error bars indicate SEM.

ure $12 C$, group averages of this eCAP amplitude modulation are depicted as percentage of the maximum eCAP amplitude. Amplitude modulation was significantly larger for $14 W D$ than for $\mathrm{NH}$ animals, although overall differences among groups were not statistically significant (one-way ANOVA; $F_{(4,29)}=2.4 ; p=0.07$; post hoc multiple comparison with Bonferroni correction: $\mathrm{NH}$ $14 W D, p=0.02)$.

eCAP characteristics in relation to SGC packing density Single-pulse eCAP characteristics for which the IPG effect was significantly different among groups (amplitude, level ${ }_{50 \%}$, and latency; see Fig. 10; Table 2) were evaluated with respect to their relation to SGC packing density. In addition, the relation between eCAP amplitude modulation and SGC packing density was assessed (Fig. 13). There was a significant correlation between each of these four functional measures and SGC packing density for the $\mathrm{NH}$ and $14 \mathrm{WD}$ (i.e., untreated) groups. Except for amplitude (Fig. 13A, dashed lines), these correlations were highly similar to those found for acutely implanted animals (Ramekers et al., 2014, 2015). Overall, the BDNF-treated groups are located in close proximity to the regression lines. Importantly, however, for level $_{50 \%}$ (Fig. 13B), these groups were clearly below the regression line (unpaired Student's $t$ test; BDNF0: $p=0.02$; BDNF4: $p=$ 0.06; BDNF8: $p<0.001$ ), suggesting that the SGC function of BDNF-treated SGCs is more similar to that of healthy SGCs in $\mathrm{NH}$ animals than their respective SGC packing densities would imply.

\section{Discussion}

Sustained SGC survival after treatment cessation

This study confirmed that SGC degeneration was averted during BDNF treatment, as demonstrated in numerous studies performed with several neurotrophic factors, including BDNF (for review, see Ramekers et al., 2012). Strikingly, no significant loss of SGCs was observed up to 8 weeks after treatment cessation, which strengthens previous findings showing sustained preservation of SGCs several weeks after cessation of treatment with BDNF or GDNF (Maruyama et al., 2008; Agterberg et al., 2009; Fransson et 
A

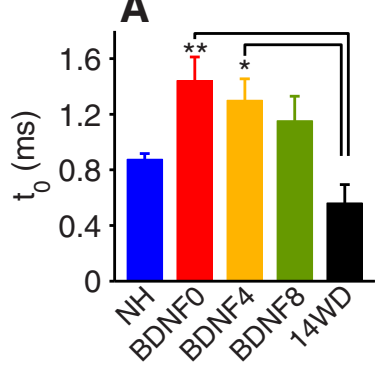

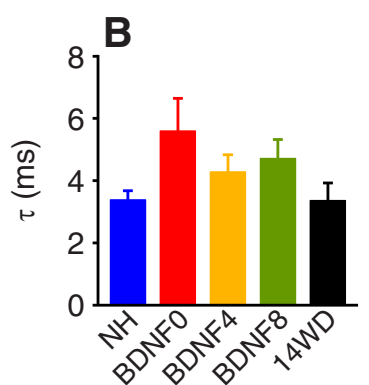

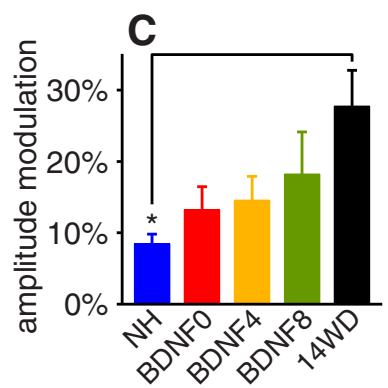

Figure 12. Group averages of eCAP characteristics obtained with pulse train stimulation. $A$, Absolute refractory period $t_{0} . B$, Recovery time constant $\tau$. C, eCAP amplitude modulation. $N H, N=6 ; B D N F 0, N=6 ; B D N F 4, N=9 ; B D N F 8, N=7 ; 14 W D, N=$ 6. ${ }^{*} p<0.05$. ${ }^{* *} p<0.01$. Error bars indicate SEM.

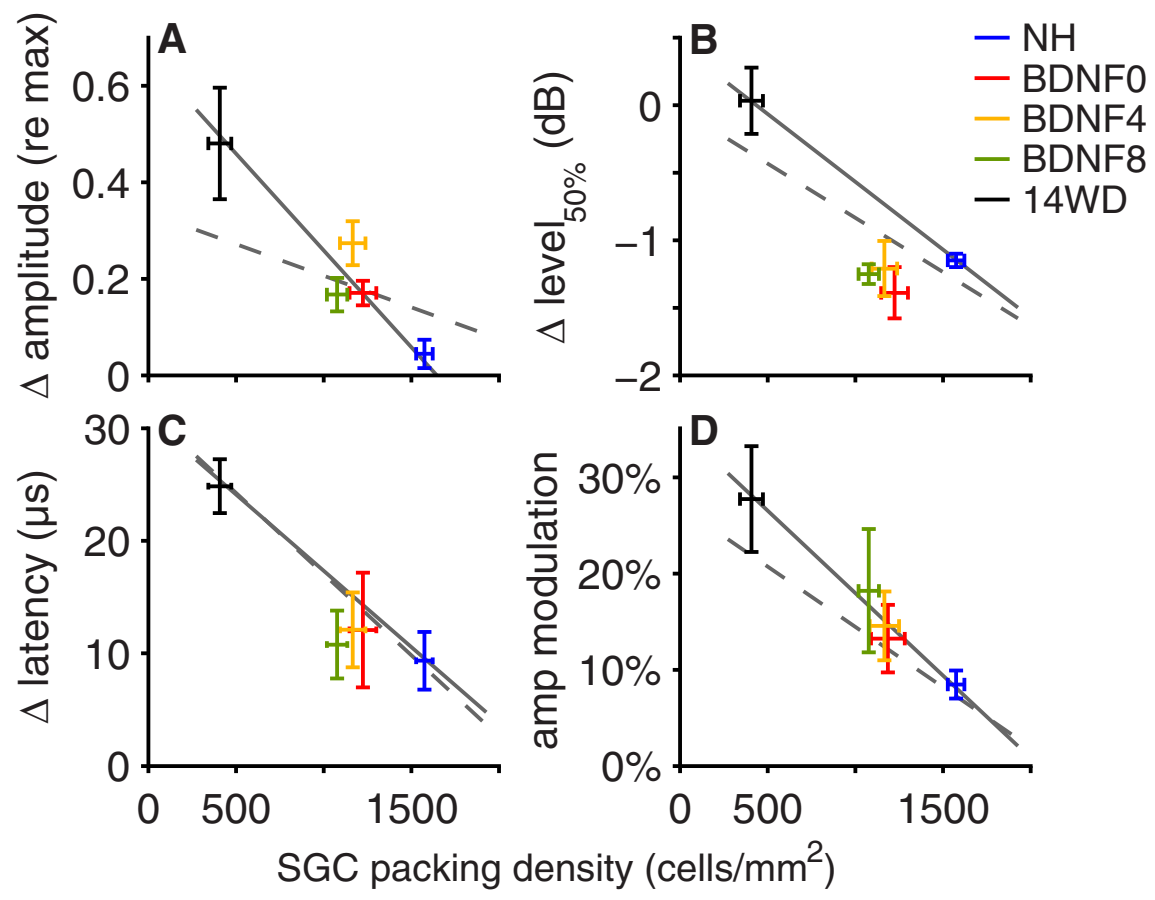

Figure 13. Group averages of eCAP characteristics plotted as a function of their average $\mathrm{SGC}$ packing density. $\boldsymbol{A}$, The change in amplitude as a result of IPG increase from 2.1 to $30 \mu$ s (see also Fig. 10). $\boldsymbol{B}$, The change in level ${ }_{50 \%}$ as a result of IPG increase. $\boldsymbol{C}$, The change in latency as a result of IPG increase. $D$, eCAP amplitude modulation obtained with pulse train stimulation. Solid lines indicate regression lines for NH and 14WD groups only; $R^{2}$ values for these regressions ranged from 0.60 to 0.71 ( $p \leq 0.003$ ). Dashed lines indicate regression lines from data previously obtained in similar experiments (Ramekers et al., 2014, 2015); these regressions showed statistically significant relationships for level ${ }_{50 \%}$ latency, and amplitude modulation.

al., 2010). Since Gillespie et al. (2003) reported SGC degeneration after treatment cessation in the absence of electrical stimulation, Agterberg et al. (2009) suggested that electrical stimulation of SGCs as performed during weekly eABR recordings in all three aforementioned studies may have been sufficiently neurotrophic. The present findings, however, reject this notion, because electrical stimulation during BDNF treatment was limited to $5 \mathrm{~min}$, and electrical stimulation after treatment was applied immediately before death. The continued survival of SGCs may involve the establishment of an autocrine neurotrophic mechanism (Ramekers et al., 2012). Autocrine BDNF signaling has been shown to mediate growth and survival of mature neurons (Davies and Wright, 1995) and pituitary melanotrope cells (Kuribara et al., 2011).

A cochleotopic gradient in SGC survival emerged after treatment cessation (Fig. 7), which has been reported repeatedly (e.g., van Loon et al., 2013). An intuitive explanation for this gradient is that BDNF was infused from the cochlear base, causing a perilymphatic concentration gradient. However, this should not lead to lower survival in the apical region because endogenous BDNF levels in normal-hearing guinea pigs are $\sim 10 \mathrm{pg} / \mathrm{ml}$ (Ito et al., 2005). Moreover, infusion with very low BDNF concentrations $(50 \mathrm{ng} / \mathrm{ml}$ ) may be effective (Miller et al., 1997). A more likely explanation follows from cochleotopic gradients in neurotrophic signaling in the healthy mature cochlea: expression levels of NT-3 are highest in the apex, whereas BDNF expression is thought to be higher in the cochlear base (Davis, 2003). Administration of exogenous BDNF will therefore have a more pronounced effect basally than apically. This notion is supported by the absence of a survival gradient when BDNF is coadministered with NT-3 (Wise et al., 2005) or with fibroblast growth factor (Glueckert et al., 2008), and by the finding that BDNF protects basal SGCs more potently than NT-3 does (Miller et al., 1997).

Because BDNF was infused through the electrode array, complete removal of the source of BDNF after the 4 week treatment was not possible. The small quantity that still remained in the cannula may therefore have contributed to the sustained survival of SGCs. However, of this small quantity, only a fraction would have diffused into the cochlea (see Materials and Methods), and its contribution to the strong sustained survival may be considered negligible.

\section{SGC size}

Immediately after BDNF treatment, SGCs were larger than normal as commonly reported (e.g., Agterberg et al., 2008). Subsequently, in contrast to the stabilized SGC packing density, the cells shrank after treatment cessation, as also observed by Agterberg et al. (2009). The opposing responses in terms of number (Fig. 7) and size (Fig. 8) to treatment, and discontinuation thereof, strongly imply two separate mechanisms of action. This notion is supported by studies using GDNF, which have shown SGC preservation while the cell size was not affected (Scheper et al., 2009; Fransson et al., 2010). The fact that SGCs in the entire population become smaller, whereas only a minority is lost with each time point after deafening (Fig. 9), also favors the existence of two separate mechanisms (van Loon et al., 2013).

\section{Effect of BDNF on eCAP measures}

We examined a wide variety of eCAP-derived variables to address the crucial question how the auditory nerve, successfully protected by BDNF, responds to electrical stimulation. Changes in eCAPs with varying IPG or with varying IPIs had been shown to correlate with neural survival (Prado-Guitierrez et al., 2006; Ramekers et al., 2014, 2015). In four measures, these correlations were clearly confirmed by the control data of the present study (Fig. 13). For each of these measures, the BDNF-treated nerves, 
regardless of time interval after treatment cessation, functioned as expected based on SGC packing density. Thus, along with preserving the SGCs, BDNF treatment preserved their responsiveness, and cessation of treatment did trigger neither degeneration nor deterioration of responsiveness.

In case of the IPG-difference measure of level ${ }_{50 \%}$ (Fig. 13B), the responses were even normal-like, suggesting improvement of responsiveness. A possible mechanism by which BDNF might cause changes in SGC function is modulation of voltage-gated ion channel expression, distribution, and activity. In in vitro experiments, Adamson et al. (2002) showed that redistribution of ion channels causes basal SGCs to exhibit apical firing properties (sustained firing) after NT-3 treatment and apical SGCs to display basal firing properties (phasic firing) after BDNF treatment. It is therefore possible that the eCAP changes we observed in BDNF-treated cochleas reflected a more "basal" composition of the SGC population. It remains to be investigated which response property (sustained vs phasic) is optimal for electrical stimulation of SGCs and, correspondingly, which neurotrophin would be most suited to apply. Alternatively, it might be crucial to preserve the natural base-to-apex gradient in firing properties by coadministration of BDNF and NT-3 (Needham et al., 2012).

Because sound encoding with CIs depends on high-rate stimulation, a vital prerequisite for clinical application of BDNF is a limited effect on temporal response properties of the auditory nerve. When stimulated by pulse trains, BDNF-treated ears tend to recover more slowly than untreated control ears (Figs. 5B, 12). Importantly, the recovery improved toward normal values after treatment cessation. The transient BDNF-induced increase in SGC size may initially affect temporal responsiveness because membrane capacitance is linearly related to soma diameter (Limón et al., 2005). Additionally, because BDNF treatment causes apical neurons to change from continuously firing to rapidly adapting under constant depolarization (Adamson et al., 2002), slower recovery arguably is a logical consequence of BDNF treatment.

Consistent with previous findings (Ramekers et al., 2015), recovery functions for masker-probe stimulation were nonmonotonic or shoulder-shaped for all animals (Figs. 5A, 11). Thus, BDNF did not fundamentally change the complex recovery dynamics. A possible mechanism underlying the increased eCAP amplitude for MPIs $\sim 1$ $\mathrm{ms}$ is a temporary increase in firing probability following recovery from refraction due to hyperpolarization-activated currents (Ramekers et al., 2015).

\section{Relative eCAP measures to assess neural responsiveness}

Following implantation, various absolute measures (threshold, level $_{50 \%}$, and latency) changed (Fig. 10). The mechanism underlying the substantial latency decrease after implantation is unclear. Changes in excitability, however (threshold and level ${ }_{50 \%}$ ), can be attributed to tissue growth. The threshold decrease agrees with previous reports in guinea pigs (Agterberg et al., 2009, 2010; Havenith et al., 2011, 2015) and human CI recipients (Hughes et al., 2001; Spivak et al., 2011). Importantly, corresponding relative measures (IPG effect) changed to a lesser extent after implantation. Hence, measures obtained with IPG variation are better suited to assess neural responsiveness because these are largely independent of implantation effects.

\section{Conclusion}

Until recently, the necessity of SGC preservation to ensure good CI performance was subject to debate, as CI performance had not been shown to be better with larger numbers of surviving SGCs (Nadol et al., 2001; Khan et al., 2005; Fayad and Linthicum,
2006). Recently, however, Seyyedi et al. (2014) found a strong positive correlation based on SGC counts and word recognition scores from both ears in bilaterally implanted patients. This finding indicates that, when higher-level processing necessary for speech perception is cancelled out, the ear that has the most SGCs systematically has better CI performance.

We have shown that brief treatment with BDNF protects SGCs for a period of time that well exceeds the treatment period itself. We argue that a specific self-sustaining mechanism, possibly an autocrine neurotrophic loop, is triggered by the exogenous BDNF. Functional properties of the SGC population are largely preserved as well, without any indication of the BDNF effect wearing off after treatment cessation. Although it remains to be investigated whether neurotrophin treatment is indeed beneficial for CI performance in humans, the present findings have shown it to be clinically practicable because temporary treatment is sufficient for longlasting effects. Temporary administration of neurotrophic factors to the human cochlea has lower risk of infection or neoplasia and is undoubtedly easier to achieve than chronic supply. Instead of osmotic pumps, gelfoam, which can carry a similar dosage as in the current study ( $20 \mu \mathrm{g})$, would be suitable as vehicle (Havenith et al., 2011, 2015). Finally, whereas chronic delivery may cause excessive sprouting of SGC peripheral processes, possibly deteriorating spatial selectivity of CIs (however, see Landry et al., 2013), temporary treatment will not give this problem because ectopic fibers retract as soon as the neurotrophin source is removed.

Because there is no reason to assume that the long-lasting effect of temporary neurotrophin treatment on both survival and function is restricted to cochlear neurons, the present findings may be valuable for treatment strategies in relation to other neurodegenerative diseases, which involve spatially restricted neuronal loss.

\section{References}

Adamson CL, Reid MA, Davis RL (2002) Opposite actions of brain-derived neurotrophic factor and neurotrophin-3 on firing features and ion channel composition of murine spiral ganglion neurons. J Neurosci 22:13851396. Medline

Agterberg MJ, Versnel H, de Groot JC, Smoorenburg GF, Albers FW, Klis SF (2008) Morphological changes in spiral ganglion cells after intracochlear application of brain-derived neurotrophic factor in deafened guinea pigs. Hear Res 244:25-34. CrossRef Medline

Agterberg MJ, Versnel H, van Dijk LM, de Groot JC, Klis SF (2009) Enhanced survival of spiral ganglion cells after cessation of treatment with brain-derived neurotrophic factor in deafened guinea pigs. J Assoc Res Otolaryngol 10:355-367. CrossRef Medline

Agterberg MJ, Versnel H, de Groot JC, van den Broek M, Klis SF (2010) Chronic electrical stimulation does not prevent spiral ganglion cell degeneration in deafened guinea pigs. Hear Res 269:169-179. CrossRef Medline

Atkinson PJ, Wise AK, Flynn BO, Nayagam BA, Richardson RT (2014) Viability of long-term gene therapy in the cochlea. Sci Rep 4:4733. CrossRef Medline

Botros A, Psarros C (2010) Neural response telemetry reconsidered: II. The influence of neural population on the ECAP recovery function and refractoriness. Ear Hear 31:380-391. CrossRef Medline

Chikar JA, Colesa DJ, Swiderski DL, Di Polo A, Raphael Y, Pfingst BE (2008) Over-expression of BDNF by adenovirus with concurrent electrical stimulation improves cochlear implant thresholds and survival of auditory neurons. Hear Res 245:24-34. CrossRef Medline

Coggeshall RE, Lekan HA (1996) Methods for determining numbers of cells and synapses: a case for more uniform standards of review. J Comp Neurol 364:6-15. CrossRef Medline

Davies AM, Wright EM (1995) Neurotrophic factors: neurotrophin autocrine loops. Curr Biol 5:723-726. CrossRef Medline

Davis RL (2003) Gradients of neurotrophins, ion channels, and tuning in the cochlea. Neuroscientist 9:311-316. CrossRef Medline

Endo T, Nakagawa T, Kita T, Iguchi F, Kim TS, Tamura T, Iwai K, Tabata Y, Ito J (2005) Novel strategy for treatment of inner ears using a biodegradable gel. Laryngoscope 115:2016-2020. CrossRef Medline 
Fayad JN, Linthicum FH Jr (2006) Multichannel cochlear implants: relation of histopathology to performance. Laryngoscope 116:1310-1320. CrossRef Medline

Fransson A, Maruyama J, Miller JM, Ulfendahl M (2010) Post-treatment effects of local GDNF administration to the inner ears of deafened guinea pigs. J Neurotrauma 27:1745-1751. CrossRef Medline

Géléoc GS, Holt JR (2014) Sound strategies for hearing restoration. Science 344:1241062. CrossRef Medline

Gillespie LN, Clark GM, Bartlett PF, Marzella PL (2003) BDNF-induced survival of auditory neurons in vivo: cessation of treatment leads to accelerated loss of survival effects. J Neurosci Res 71:785-790. CrossRef Medline

Glueckert R, Bitsche M, Miller JM, Zhu Y, Prieskorn DM, Altschuler RA, Schrott-Fischer A (2008) Deafferentation-associated changes in afferent and efferent processes in the guinea pig cochlea and afferent regeneration with chronic intrascalar brain-derived neurotrophic factor and acidic fibroblast growth factor. J Comp Neurol 507:1602-1621. CrossRef Medline

Havenith S, Versnel H, Agterberg MJ, de Groot JC, Sedee RJ, Grolman W, Klis SF (2011) Spiral ganglion cell survival after round window membrane application of brain-derived neurotrophic factor using gelfoam as carrier. Hear Res 272:168-177. CrossRef Medline

Havenith S, Versnel H, Klis SF, Grolman W (2015) Local delivery of brainderived neurotrophic factor on the perforated round window membrane in guinea pigs: a possible clinical application. Otol Neurotol 36:705-713. CrossRef Medline

Hughes ML, Vander Werff KR, Brown CJ, Abbas PJ, Kelsay DM, Teagle HF, Lowder MW (2001) A longitudinal study of electrode impedance, the electrically evoked compound action potential, and behavioral measures in nucleus 24 cochlear implant users. Ear Hear 22:471-486. CrossRef Medline

Ito J, Endo T, Nakagawa T, Kita T, Kim TS, Iguchi F (2005) A new method for drug application to the inner ear. ORL J Otorhinolaryngol Relat Spec 67:272-275. CrossRef Medline

Javel E, Shepherd RK (2000) Electrical stimulation of the auditory nerve: III. Response initiation sites and temporal fine structure. Hear Res 140:45-76. CrossRef Medline

Khan AM, Handzel O, Burgess BJ, Damian D, Eddington DK, Nadol JB Jr (2005) Is word recognition correlated with the number of surviving spiral ganglion cells and electrode insertion depth in human subjects with cochlear implants? Laryngoscope 115:672-677. CrossRef Medline

Kuribara M, Hess MW, Cazorla M, Roubos EW, Scheenen WJ, Jenks BG (2011) Brain-derived neurotrophic factor stimulates growth of pituitary melanotrope cells in an autocrine way. Gen Comp Endocrinol 170:156161. CrossRef Medline

Landry TG, Fallon JB, Wise AK, Shepherd RK (2013) Chronic neurotrophin delivery promotes ectopic neurite growth from the spiral ganglion of deafened cochleae without compromising the spatial selectivity of cochlear implants. J Comp Neurol 521:2818-2832. CrossRef Medline

Leake PA, Hradek GT, Hetherington AM, Stakhovskaya O (2011) Brainderived neurotrophic factor promotes cochlear spiral ganglion cell survival and function in deafened, developing cats. J Comp Neurol 519: 1526-1545. CrossRef Medline

Limón A, Pérez C, Vega R, Soto E (2005) $\mathrm{Ca}^{2+}$-activated $\mathrm{K}^{+}$-current density is correlated with soma size in rat vestibular-afferent neurons in culture. J Neurophysiol 94:3751-3761. CrossRef Medline

Maruyama J, Miller JM, Ulfendahl M (2008) Glial cell line-derived neurotrophic factor and antioxidants preserve the electrical responsiveness of the spiral ganglion neurons after experimentally induced deafness. Neurobiol Dis 29:14-21. CrossRef Medline

Miller JM, Chi DH, O’Keeffe LJ, Kruszka P, Raphael Y, Altschuler RA (1997) Neurotrophins can enhance spiral ganglion cell survival after inner hair cell loss. Int J Dev Neurosci 15:631-643. CrossRef Medline

Morsnowski A, Charasse B, Collet L, Killian M, Müller-Deile J (2006) Measuring the refractoriness of the electrically stimulated auditory nerve. Audiol Neurootol 11:389-402. CrossRef Medline

Nadol JB Jr, Shiao JY, Burgess BJ, Ketten DR, Eddington DK, Gantz BJ, Kos I, Montandon P, Coker NJ, Roland JT Jr, Shallop JK (2001) Histopathology of cochlear implants in humans. Ann Otol Rhinol Laryngol 110: 883-891. CrossRef Medline

Needham K, Nayagam BA, Minter RL, O'Leary SJ (2012) Combined application of brain-derived neurotrophic factor and neurotrophin-3 and its impact on spiral ganglion neuron firing properties and hyperpolarization-activated currents. Hear Res 291:1-14. CrossRef Medline

Pettingill LN, Wise AK, Geaney MS, Shepherd RK (2011) Enhanced auditory neuron survival following cell-based BDNF treatment in the deaf guinea pig. PLoS One 6:e18733. CrossRef Medline

Prado-Guitierrez P, Fewster LM, Heasman JM, McKay CM, Shepherd RK (2006) Effect of interphase gap and pulse duration on electrically evoked potentials is correlated with auditory nerve survival. Hear Res 215:47-55. CrossRef Medline

Ramekers D, Versnel H, Grolman W, Klis SF (2012) Neurotrophins and their role in the cochlea. Hear Res 288:19-33. CrossRef Medline

Ramekers D, Versnel H, Strahl SB, Smeets EM, Klis SF, Grolman W (2014) Auditory-nerve responses to varied interphase gap and phase duration of the electric pulse stimulus as predictors for neuronal degeneration. J Assoc Res Otolaryngol 15:187-202. CrossRef Medline

Ramekers D, Versnel H, Strahl SB, Klis SF, Grolman W (2015) Recovery characteristics of the electrically stimulated auditory nerve in deafened guinea pigs: relation to neuronal status. Hear Res 321:12-24. CrossRef Medline

Scheper V, Paasche G, Miller JM, Warnecke A, Berkingali N, Lenarz T, Stöver T (2009) Effects of delayed treatment with combined GDNF and continuous electrical stimulation on spiral ganglion cell survival in deafened guinea pigs. J Neurosci Res 87:1389-1399. CrossRef Medline

Seyyedi M, Viana LM, Nadol JB Jr (2014) Within-subject comparison of word recognition and spiral ganglion cell count in bilateral cochlear implant recipients. Otol Neurotol 35:1545-1551. CrossRef Medline

Shepherd RK, Coco A, Epp SB, Crook JM (2005) Chronic depolarization enhances the trophic effects of brain-derived neurotrophic factor in rescuing auditory neurons following a sensorineural hearing loss. J Comp Neurol 486:145-158. CrossRef Medline

Shinohara T, Bredberg G, Ulfendahl M, Pyykkö I, Olivius NP, Kaksonen R, Lindström B, Altschuler R, Miller JM (2002) Neurotrophic factor intervention restores auditory function in deafened animals. Proc Natl Acad Sci U S A 99:1657-1660. CrossRef Medline

Spivak L, Auerbach C, Vambutas A, Geshkovich S, Wexler L, Popecki B (2011) Electrical compound action potentials recorded with automated neural response telemetry: threshold changes as a function of time and electrode position. Ear Hear 32:104-113. CrossRef Medline

Spoendlin H (1975) Retrograde degeneration of the cochlear nerve. Acta Otolaryngol 79:266-275. CrossRef Medline

Staecker H, Garnham C (2010) Neurotrophin therapy and cochlear implantation: translating animal models to human therapy. Exp Neurol 226:1-5. CrossRef Medline

Stroh M, Zipfel WR, Williams RM, Ma SC, Webb WW, Saltzman WM (2004) Multiphoton microscopy guides neurotrophin modification with poly(ethylene glycol) to enhance interstitial diffusion. Nat Mater 3:489494. CrossRef Medline

Stronks HC, Versnel H, Prijs VF, Klis SF (2010) Suppression of the acoustically evoked auditory-nerve response by electrical stimulation in the cochlea of the guinea pig. Hear Res 259:64-74. CrossRef Medline

van Loon MC, Ramekers D, Agterberg MJ, de Groot JC, Grolman W, Klis SF, Versnel H (2013) Spiral ganglion cell morphology in guinea pigs after deafening and neurotrophic treatment. Hear Res 298:17-26. CrossRef Medline

Versnel H, Agterberg MJ, de Groot JC, Smoorenburg GF, Klis SF (2007) Time course of cochlear electrophysiology and morphology after combined administration of kanamycin and furosemide. Hear Res 231:1-12. CrossRef Medline

West BA, Brummett RE, Himes DL (1973) Interaction of kanamycin and ethacrynic acid: severe cochlear damage in guinea pigs. Arch Otolaryngol 98:32-37. CrossRef Medline

Wise AK, Richardson R, Hardman J, Clark G, O’Leary S (2005) Resprouting and survival of guinea pig cochlear neurons in response to the administration of the neurotrophins brain-derived neurotrophic factor and neurotrophin-3. J Comp Neurol 487:147-165. CrossRef Medline

Wise AK, Fallon JB, Neil AJ, Pettingill LN, Geaney MS, Skinner SJ, Shepherd RK (2011) Combining cell-based therapies and neural prostheses to promote neural survival. Neurotherapeutics 8:774-787. CrossRef Medline

Ylikoski J, Wersäll J, Bjorkroth B (1974) Degeneration of neural elements in the cochlea of the guinea pig after damage to the organ of Corti by ototoxic antibiotics. Acta Otolaryngol Suppl 326:23-41. Medline 